\title{
The hyperfunction theory: an emerging paradigm for the biology of aging
}

\author{
David Gems
}

\begin{abstract}
Institute of Healthy Ageing, and Research Department of Genetics, Evolution and Environment, University College London, London WC1E 6BT, UK

* Correspondence: David Gems, Institute of Healthy Ageing, and Department of Genetics, Evolution and Environment, University College London, Gower Street, London WC1E 6BT, United Kingdom; david.gems@ucl.ac.uk
\end{abstract}

\begin{abstract}
The process of senescence (aging) is largely determined by the action of wild-type genes. For most organisms, this does not reflect any adaptive function of senescence, but rather evolutionary effects of declining selection against genes with deleterious effects later in life. To understand aging requires an account of how evolutionary mechanisms give rise to pathogenic gene action and late-life disease, that integrates evolutionary (ultimate) and mechanistic (proximate) causes into a single explanation. A well-supported evolutionary explanation by G.C. Williams argues that senescence can evolve due to pleiotropic effects of alleles with antagonistic effects on fitness and late-life health (antagonistic pleiotropy, AP). What has remained unclear is how gene action gives rise to latelife disease pathophysiology. One ultimate-proximate account is T.B.L. Kirkwood's disposable soma theory. Based on the hypothesis that stochastic molecular damage causes senescence, this reasons that aging is coupled to reproductive fitness due to preferential investment of resources into reproduction, rather than somatic maintenance. An alternative and more recent ultimate-proximate theory argues that aging is largely caused by programmatic, developmental-type mechanisms. Here ideas about AP and programmatic aging are reviewed, particularly those of M.V. Blagosklonny (the hyperfunction theory) and J.P. de Magalhães (the developmental theory), and their capacity to make sense of diverse experimental findings is described.
\end{abstract}

Keywords: antagonistic pleiotropy; insulin/IGF-1 signalling; hyperfunction; quasi-programs; mTOR; theories of aging; programmatic aging 


\section{Contents}

1. Introduction

2. The evolution of aging

2.1. Antagonistic pleiotropy as a cause of aging

3. Ultimate-proximate theory 1. Disposable soma: where damage causes aging

4. Ultimate-proximate theory 2 . Where aging is programmatic

4.1 The core programmatic theory

5. Mikhail Blagosklonny

5.1 Blagosklonny's research approach

5.2 How do quasi-programs promoted by IIS/mTOR limit lifespan?

5.2.1 Aging is pathology

5.2.2 Aging as a nested series of life-limiting etiologies

5.2.3 Non-cell autonomous action of quasi-programs

5.2.4 Programmatic etiologies as a target for intervention

5.2.5 Pathogenic effects of mTOR acting as a brake on growth

5.2.6 Programmatic loosening as a feature of aging

5.3 Blagosklonny on the attack

5.3.1 Against the oxidative damage theory

5.3.2 Against disposable soma

5.3.3 Against stress-response hormesis

6. João Pedro de Magalhães

6.1 From developmental theories to the programmatic theory

6.2 From the programmatic theory to epigenetic aging and biological clocks

7. Vladimir Dilman: programmatic aging within a multifactorial model

7.1 Dilman's ontogenetic and four models theories

7.2 A new multifactorial model based on Dilman's four models theory

7.3 The ontogenesis of the programmatic theory

8. Concluding remarks

References

Glossary 


\section{Introduction}

As a field, the biology of senescence (aging) is lacking in terms of a core explanatory framework or paradigm such as those possessed by chemistry or genetics (Gems and de Magalhães, 2021). This review summarizes an emerging set of ideas which for convenience will be referred to here as the programmatic theory. It describes how they can provide a possible explanation for the proximate mechanisms of antagonistic pleiotropy, an important evolutionary-genetic principle in the biology of aging (Williams, 1957). However, it should be emphasized from the outset that the programmatic theory does not claim to explain the whole of aging.

Devising effective explanations of senescence as a whole is a challenge that has, unfortunately, defeated biogerontologists. Why is aging so difficult to understand? Arguably, there are two reasons in particular. First, because it is a multifactorial process, as reflected in the fact that diseases of aging are largely multifactorial in terms of their etiology. Thus, any individual theory about a given senescent etiology will be insufficient to explain the whole phenomenon. Second, because the relative contribution of the factors that together cause aging is variable and highly context dependent, differing according to the senescent pathology considered, to environmental conditions and type of organism (Ezcurra et al., 2018; Gems and de Magalhães, 2021).

Though this presents a difficult challenge, it does not mean that senescence is impossible to understand. Though aging is a multifactorial process, a plausible hope is that the number of individual factors involved is relatively small, particularly when viewed in terms of broad determinative principles. Moreover, given the common evolutionary origins of animal species, these principles are likely to be operative in diverse organisms. Thus, the challenge for biogerontology is to understand these individual principles, and how they combine to cause aging-related disease, and aging as a whole (Gems and de Magalhães, 2021).

While attempts to understand aging from the 1990s onwards focused particularly on the role of accumulation of molecular damage as a cause of aging, earlier accounts tended to be more broadly multifactorial (Comfort, 1979; Cutler, 1984; Dilman, 1994; Finch, 1990; Strehler, 1977). Multifactorial models, particularly that of Vladimir Dilman, will be discussed later in this article. In the meantime, I emphasize that programmatic mechanisms and antagonistic pleiotropy (AP) as described here should be viewed as elements of a wider, multifactorial process.

In the following discussion I will first introduce the concept of $\mathrm{AP}$, as described by George Williams, and then go on to describe attempts to explain AP in terms of actual biological mechanisms (e.g. biochemical, cellular, developmental) that form a pathophysiological basis of the process of senescence (aging). These include Tom Kirkwood's disposable soma theory, Misha Blagosklonny's hyperfunction theory, João Pedro de Magalhães's developmental theory, and Vladimir Dilman's ontogenetic theory. The latter three theories share key features, and can be referred to collectively as the programmatic theory. For definitions of key terms, see the glossary.

\section{The evolution of aging}

Diseases of aging are strange in that their principal etiology is not any of the usual suspects (infectious pathogens, mechanical injury, 
mutation, toxins etc), but rather the process of evolution. Natural selection favors individuals that leave the largest number of surviving offspring, not necessarily those that live the longest. With advancing age after the onset of reproduction, natural selection weakens with the result that new alleles that impair health in later life are more likely to escape selection and accumulate in populations, causing aging (Medawar, 1952). The causes of this selection shadow can include extrinsic factors (e.g. predation, starvation) that increase mortality disproportionately in later life (Abrams, 1993; Hamilton, 1966; Moorad et al., 2019).

\subsection{Antagonistic pleiotropy as a cause of aging}

How might gene variants with bad effects on late-life health act? Here there are two ideas. First, they could be harmful mutations with effects that do not appear until late life. For example, Huntington's disease does not develop until mid-life, as the selection shadow deepens. This could explain its relatively high prevalence, despite being caused by a dominant mutation (Haldane, 1941). This instantiates the mutation accumulation theory of the evolution of aging (Medawar, 1952). Here, the harmful alleles that natural selection fails to eliminate and which cause aging are very much akin to disease-causing mutations, such as those causing Marfan syndrome or hemochromatosis. According to the mutation accumulation theory aging is a form of genetic disease, arising from a multiplicity of mutations.

Second, they may be gene variants that provide a fitness benefit in early life, but also promote pathology in later life. Due to the selection shadow, fitness benefits may outweigh the later detriment, resulting in the allele spreading through the population (Williams, 1957)(Figure 1A). Here the new allele displays pleiotropy, i.e. has several effects, that are opposite in terms of impact on fitness, i.e. antagonistic pleiotropy (AP). Given that AP genes provide fitness benefits, they cannot be viewed as defective or mutant; rather they are, in genetic terms, wild type. Thus, insofar as they are caused by AP genes, diseases of aging are genetic diseases arising from effects of the wild-type genome. The idea that normal gene function can cause disease may, from a medical perspective, seem a contradiction in terms. But evolutionary theory, now well supported empirically (Gaillard and Lemaître, 2017; Nesse and Williams, 1994; Zhao and Promislow, 2019), tells us that normal genes can cause late-life pathology.

This is a fundamental principle of pathophysiology critical for understanding late-life disease. Yet its utility is limited by the current lack of understanding of the actual biological mechanisms (biochemical, cellular, physiological) by which AP genes exert their effects. What is needed here is an account of the determinants of aging that encompasses both ultimate, evolutionary mechanisms and proximate, biological mechanisms into a single integrated understanding. Two such ultimateproximate accounts of the causes of aging are the disposable soma theory and the programmatic theory.

\section{Ultimate-proximate theory 1. Disposable soma: where damage causes aging}

For many years a popular hypothesis about aging has been that its principal cause is the accumulation of random molecular damage (Harman, 1956; Shore and Ruvkun, 2013; Zimniak, 2008). It was thought that such damage arises in particular from reactive oxygen species (ROS) such as the superoxide $\left(\mathrm{O}_{2}{ }^{-}\right)$free radical produced as a by-product of 
oxidative metabolism (Beckman and Ames, 1998). From this it follows that the level of cellular maintenance that prevents damage accumulation is an important determinant of aging rate, and that the genetic determination of lifespan is likely to involve regulation of cellular maintenance mechanisms (Partridge and Gems, 2006). In short, aging rate reflects the balance between stochastic damage accumulation and somatic maintenance levels (the damage/maintenance paradigm) (Figure 1B).

The observation that cellular maintenance processes are costly in resource terms led to the deduction that trade-offs might exist between cellular maintenance and reproductive effort. Given limited resource availability in the wild, optimization of the trade-off would inevitably lead to levels of cellular maintenance below those necessary to entirely prevent damage accumulation. The result of this is a rapidly aging, disposable soma, in contrast to the immortal, non-aging germline (Kirkwood, 2005; Kirkwood, 1977) (Figure 1C).

The disposable soma (DS) theory provides a clear and logical account of how trade-offs could arise between fitness traits at different points in the life history: early benefit (increased reproduction) and later cost (increased mortality due to damage accumulation). Though not originally conceived as such (Armstrong, 2019) it provides a cogent explanation for the proximate mechanisms of AP gene action (Kirkwood and Rose, 1991). Yet despite its elegance, the DS theory remains unproven, and some experimental findings clearly argue against it (Grandison et al., 2009; Piper et al., 2017; Zajitschek et al., 2019). One limitation is its dependence upon the damage/maintenance paradigm. While molecular damage, DNA damage in particular (Schumacher et al., 2021), is certainly a primary causal mechanism in some forms of senescent pathology (e.g. cancer), for many others this is far from clear (see below). While it is possible that DS effects could exacerbate pathologies where damage is a major driver, their importance as a major cause of aging currently seems unlikely (discussed further below) (Blagosklonny, 2007b; Blagosklonny, 2010e). But while its explanatory utility remains uncertain, as the first ultimate-proximate model, the DS theory was important in providing a template for the development of ultimate-proximate theories.

\section{Ultimate-proximate theory 2 . Where aging is programmatic}

In the early 2000s it became increasingly clear that the insulin/IGF-1 signaling (IIS)/ mammalian (or mechanistic) target of rapamycin (mTOR) network can control aging rate across a range of organisms (Gems and Partridge, 2001; Kenyon, 2010). Discovering the IIS/mTOR-regulated, downstream mechanisms of aging itself promised to provide fundamental insights into the nature of senescence. Guided by contemporary beliefs, early attempts to understand this guessed that wild-type IIS accelerated aging by reducing somatic maintenance (e.g. antioxidant defense) thereby increasing reproductive output, consistent with the DS theory (Fontana et al., 2010; Gems and McElwee, 2005; Holzenberger et al., 2003; Honda and Honda, 1999; Kirkwood, 2005; Lithgow and Walker, 2002; Partridge and Gems, 2002b; Vanfleteren, 1993) (Figure 1D). However, during the same period doubts were beginning to emerge about the assumption that molecular damage is a primary cause of aging, particularly oxidative damage (Bjelakovic et al., 2007; Chong et al., 2007; Howes, 2006; Keaney and Gems, 2003; Keaney et al., 2004).

Against this background, two biogerontologists independently saw a way to rearrange existing concepts and findings 
into a new ultimate-proximate theory that is very different to DS. Although initial accounts of the theory, put forward by João Pedro de Magalhães (de Magalhães and Church, 2005) and Mikhail Blagosklonny (Blagosklonny, 2006a), differ in emphasis and in detail, they have the same conceptual core (the programmatic theory). de Magalhães and Blagosklonny each put forward many ideas, some more persuasive than others; the following account of the framework of ideas centered on the programmatic theory is to a certain extent my own synthesis of their ideas.

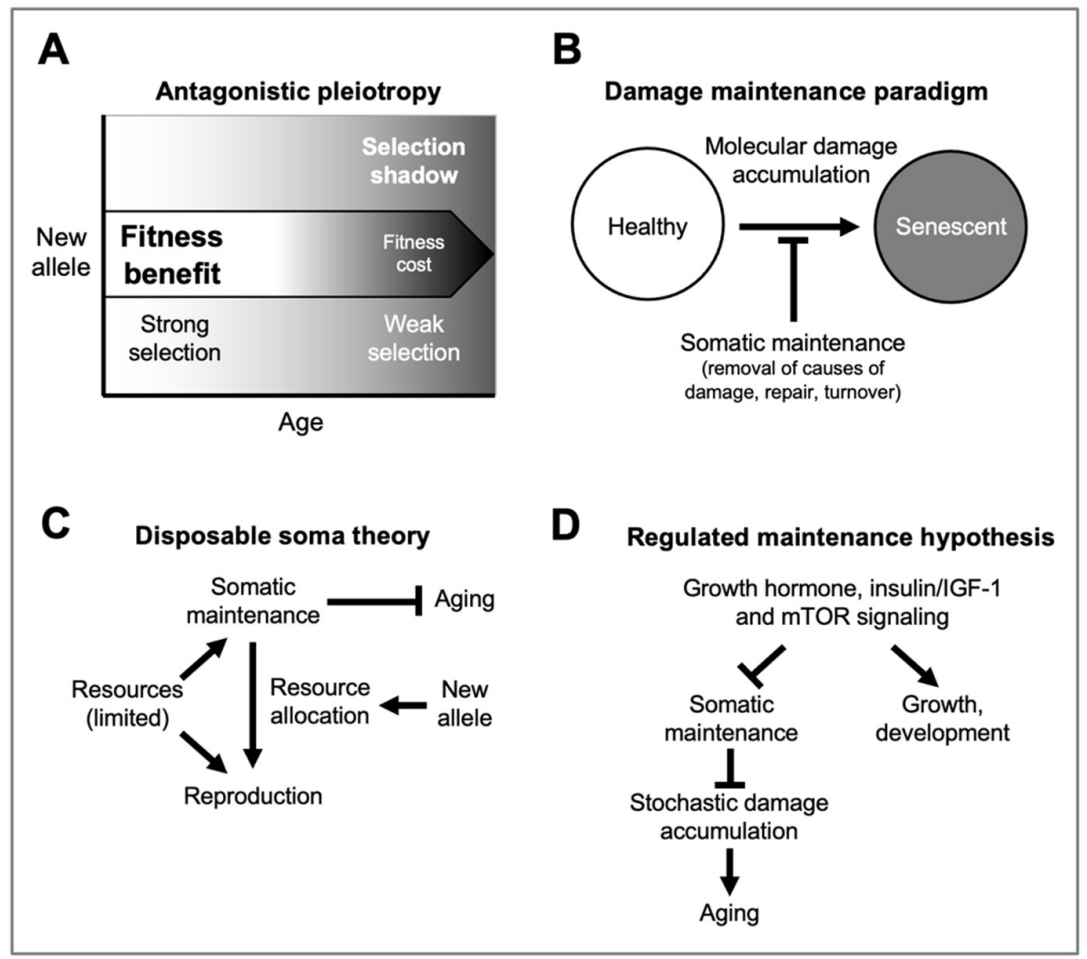

Figure 1. Ultimate and proximate mechanisms of aging. A, Antagonistic pleiotropy. A new allele that causes a fitness benefit in early life but a fitness cost (e.g. increased pathology) in later life may cause a net benefit in overall fitness due to the selection shadow (Williams, 1957). B, The damage/maintenance paradigm. Aging is caused by accumulation of stochastic molecular damage, whose levels can be controlled by somatic maintenance functions. C, The disposable soma theory. Investment of resources in reproduction more than somatic maintenance can increase fitness due to the selection shadow (Kirkwood, 1977). Genes promoting such resource allocation will exhibit antagonistic pleiotropy (Partridge and Gems, 2002a). D, Regulation of aging by nutrient pathways. Traditional view based on damage/maintenance paradigm (Partridge and Gems, 2006). The hyperfunction model argues that it is in fact the growth, development function that plays the main role in promoting aging.

\subsection{The core programmatic theory}

Growth hormone $(\mathrm{GH})$, IIS and mTOR are part of a nutrientsensitive signaling network that promotes growth, development and aging. This suggests that growth and development somehow cause aging. But three lines of reasoning initially seemed to argue against this deduction. First, it suggests that there is a program for aging, implying that aging is a purposeful adaptation; but according to evolutionary theory aging is non-adaptive, and therefore not programmed (Austad, 
2004; Kirkwood, 2005; Partridge and Gems, 2002b). Second, growth and development are not obviously linked to somatic maintenance and molecular damage accumulation, which was assumed to be the main cause of senescence. Third, it is difficult to see how growth processes can limit lifespan. The programmatic theory provides answers to each of these three objections.

First, the program problem. Here it is helpful to consider Williams' own initial thoughts about how AP might work at the level of gene function, which involve a hypothetical gene for calcium deposition. A new allele appears that increases $\mathrm{Ca}^{2+}$ deposition during bone development, and thereby promotes fitness (e.g. by aiding escape from predators); in later life, its continued action promotes $\mathrm{Ca}^{2+}$ deposition into blood vessel walls, contributing to arteriosclerosis (Figure 2A) (Williams, 1957). In principle, a mechanism could evolve to switch off calcium deposition, but due to the selection shadow it does not. Here, an evolved function of a gene continues or runs on in a futile fashion in later life causing pathology. The principle involved here is notably different to the DS theory. If this can occur for the function of structural genes of this sort, why not for regulatory genes controlling entire developmental programs and involving action of large numbers of regulated genes (Figure 2B).

Evolutionary theory rules out biological programs for aging (i.e. aging as an adaptation) for most species, but not programmatic or program-like mechanisms that promote senescence (Blagosklonny, 2007c; de Magalhães and Church, 2005). Part of the confusion arises because the word program here has two meanings. On the one hand it can mean a genetically-determined and complex process involving changes in gene expression, cellular function, tissue composition etc (programmed in the mechanistic sense); on the other hand it can mean a program for something that promotes fitness (programmed in the adaptive sense)(Galimov et al., 2019). Aided by this disambiguation, the new theory is able to argue that in later life programmatic changes occur that are programmed in the mechanistic but not the adaptive sense, or as Blagosklonny describes them, quasi-programmed (Blagosklonny, 2006a). The derived noun quasiprogram, describing a programmatic, pathogenic entity, is particularly useful for discussion of programmatic pathophysiology.

To explain the quasi-program concept, Blagosklonny uses various homely analogies. For example, one wants hot water for tea and so boils some in a saucepan. If, having taken the water, one leaves the saucepan on the hot stove, the pan will become damaged. Here a purposeful program for preparing hot water becomes a futile quasiprogram for damaging the saucepan (Blagosklonny, 2006a). In living organisms later-life off switches for developmental programs are often absent because of declining selection in later life (Blagosklonny, 2006a; Williams, 1957). Similarly, de Magalhães uses the analogy of a program to build a house, and imagines a carpet layer working on pointlessly after completion of the program: "ever-increasing layers of carpets will eventually prevent doors from opening, and ultimately, nobody will be able to get in or out of the house" (de Magalhães, 2012). This starts to explain how growth promotion by IIS/mTOR can promote aging: they promote both developmental programs and senescence-promoting quasi-programs. (Blagosklonny, 2006a; de Magalhães and Church, 2005)? 


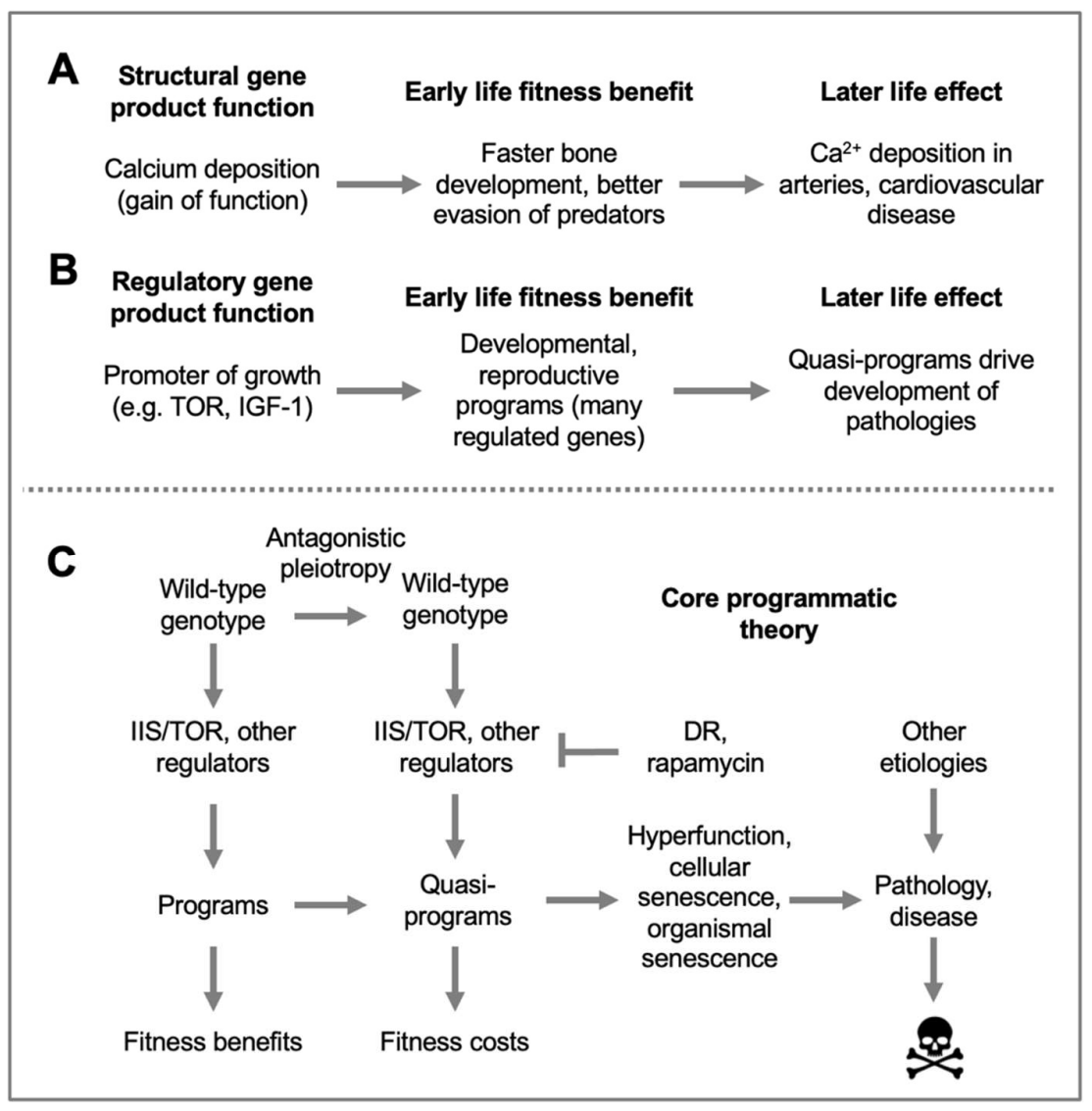

Figure 2. Antagonistic pleiotropy (AP) as hyperfunction. A, AP as run-on of structural gene function. Hypothetical example (Williams, 1957). B, AP as runon of regulatory gene function. This results in pathogenic quasi-programs (Blagosklonny, 2006a). C, Overview of the core programmatic theory of aging (Blagosklonny, 2006a; de Magalhães and Church, 2005); here passage from left to right denotes advancing age. See glossary for definition of terms.

But what about molecular damage? de Magalhães and Blagosklonny both suggest that the assumption that aging is largely and primarily caused by accumulation of molecular damage is incorrect (Blagosklonny, 2006a; de Magalhães and Church, 2005). This view is broadly shared by Williams: "In thinking of senescence, the analogy to wear and tear, or corrosion, or other processes that ultimately cause an artificial device to fail is utterly misleading" (Williams, 1996). As Blagosklonny articulates it, the primary mechanisms of aging do not involve loss of function, but rather the opposite: too much function or, as he puts it, hyperfunction, driven by wild-type gene action. This claim challenges the entrenched assumption that aging is fundamentally a passive process of system failure and breakdown. Thinking of mTOR effects in particular, Blagosklonny argues that it is the opposite: an active, self-destructive process.

Finally, how can processes of growth and development lead to disease? Broadly speaking, the programmatic theory argues that developmental changes in adulthood, including late-life continuation of developmental programs, is pathogenic, causing disruption of tissue and organ function. Several examples of simple forms of developmental runon follow. Presbyopia is a type of long-sightedness that increases with age. Its cause is continued, futile growth of the lens during adulthood, leading to a gradual increase in lens thickness (Strenk et al., 2005). In men, 
the prostate gland typically exhibits a gradual increase in size as a response to long term exposure to dihydrotestosterone. This leads eventually to benign prostatic hyperplasia (Nacusi and Tindall, 2011; Waters et al., 2000) and increased risk of prostate cancer, a major cause of age-related death in men (Untergasser et al., 2005). In a third example, this time hypothetical, the process of synaptic pruning in the brain that promotes cognitive development runs on in later life, leading to agerelated cognitive decline (De Magalhaes and Sandberg, 2005). A final example affects babirusas, a type of wild pig found in Indonesia. Adult males have curved, tusk-like maxillary canine teeth that point backwards up over the snout. These continue to grow until in some cases the backward curve of their growth trajectory drives them into the cranium, sometimes piercing it through (Macdonald, 2018). Here, in each case, continuation of normal, wild-type growth leads to pathology. However, most aging-related diseases are etiologically multi-factorial, and contributions of programmatic etiologies more complex (described below).

A simplified scheme of the programmatic theory is shown in Figure 2C. Beyond these core tenets, Blagosklonny and de Magalhães each contribute additional ideas, which extend and strengthen the theorem. For example, Blagosklonny elaborates upon how quasiprograms affect lifespan and disease, and makes pointed critiques of various concepts arising from the damage/maintenance paradigm, while de Magalhães integrates the programmatic theory conceptually with earlier developmental theories of aging, and explores evolutionary mechanisms beyond AP and IIS/mTOR that contribute to programmatic aging. Ideas from these two commentators will be discussed in turn.

\section{Mikhail Blagosklonny}

\subsection{Blagosklonny's research approach}

To understand Blagosklonny's thinking it is helpful to know something about his background and approach. Unlike most biogerontologists, he has a clinical background (M.D. in internal medicine, Ph.D. in experimental medicine and cardiology). He is a proponent and practitioner of conceptual research, which uses explorations of the scientific literature to develop new hypotheses and to test them, sometimes repurposing existing data to draw new conclusions in ways unintended by the original researchers (Blagosklonny, 2007d; Blagosklonny and Pardee, 2002). He initially applied this approach for research in experimental oncology, including a focus on anti-cancer drug action (Blagosklonny, 2005a; Blagosklonny, 2005b; Blagosklonny, 2005c). An interest in the potential of the drug rapamycin as an anti-cancer agent (Blagosklonny and Darzynkiewicz, 2002) led him to the idea that this drug might act by inhibiting aging. This led in turn to the question of the causes of aging itself, and a re-examination of central ideas in biogerontology, both ultimate (e.g. antagonistic pleiotropy, disposable soma) and proximate (e.g. molecular damage accumulation, telomere shortening).

A strength of conceptual research is the relative ease of combining findings and concepts from different scientific disciplines, for example between basic and clinical research fields (Blagosklonny, 2003b), enabling broader insights. Blagosklonny's conclusions draw extensively from both biogerontological sources and, importantly, clinical literature on age-related disease; thus, his ideas are more strongly grounded in contemporary research findings (including clinical findings) than in 
traditional theories about aging. They are also influenced by earlier ideas developed in Russia in the 1970-80s (Dilman, 1994) (discussed further below).

Given that the starting point of the work was to understand the action of rapamycin, his perspective is highly focused on this drug and the protein that it inhibits, mTOR (Blagosklonny, 2007a; Blagosklonny, 2010b; Blagosklonny, 2012c; Blagosklonny, 2014b; Blagosklonny, 2019a), which restricts its scope somewhat. However, his arguments are often applicable (and applied) to the broader endocrine and signalling network that regulates development and growth, including GH and IIS. In many of his discussions, the aging process that he describes is the set of processes controlled by GH/IIS/mTOR which, as he sometimes emphasises, is not the entire aging process.

Key to the initial development of Blagosklonny's theorem was his realization that growth stimulation leads rapidly to cellular senescence when the cell cycle is arrested, with no involvement of molecular damage (Blagosklonny, 2003a). His main ideas are set out in three early essays (Blagosklonny, 2006a; Blagosklonny, 2007b; Blagosklonny, 2008b), particularly the first of these. He then produced a very long series of follow-up essays (more than 60!), some derived from additional conceptual research with newer findings, and some responding to individual new papers. Many of these essays argue that an mTOR hyperfunction model better explains published findings than the conventional damage-based view, and often include explanatory reiterations of his version of the programmatic theory. The repetition to an extent reflects the lack of response to his work from other biogerontologists; "Repetitio est mater studiorum" as he notes at one point (Blagosklonny, 2018b). Some present new elaborations and additions to the theory, e.g. (Blagosklonny, 2007c; Blagosklonny, 2009b; Blagosklonny, 2010c; Blagosklonny, 2010d; Blagosklonny, 2018a; Blagosklonny, 2019b). For brief summaries of the content of 65 of his essays, see Table 1 . The essays draw to some extent on his own laboratory work, mostly on the regulation of cellular senescence, see e.g. (Demidenko et al., 2009a; Demidenko and Blagosklonny, 2008; Demidenko and Blagosklonny, 2009; Demidenko et al., 2010; Demidenko et al., 2009b; Leontieva and Blagosklonny, 2016; Leontieva et al., 2015; Leontieva et al., 2012a; Leontieva et al., 2012b). At times they seem written in haste, as if painted with rough brushstrokes, but what they sometimes lack in polish they often make up for in originality and creative insight. Key elements of Blagosklonny's framework of ideas, beyond the core programmatic theory include the following.

\subsection{How do quasi-programs promoted by IIS/mTOR limit lifespan?}

Aging is a deteriorative process that causes decline and death, but how? The core programmatic AP account provides a cause, but does not explain how it leads to life-limiting harm. It is here that Blagosklonny in particular sheds light, helped by three basic ideas that combine to give a very different view of aging to that which is traditional in biogerontology. First, that death due to aging is caused by disease. Second, that aging results from a nested series of life-limiting etiologies. Third, that programmatic AP promoted by IIS/mTOR causes life-limiting disease in a largely non-cell autonomous manner.

5.2.1. Aging is pathology. Biogerontologists usually use lifespan or mortality rate as metrics of aging rather than senescent pathology, and 
tend to view aging as a process distinct from age-related disease (Gems, 2015; Hayflick, 2007). By contrast, influenced by his medical training, Blagosklonny sees aging very much in terms of diseases: “No one dies from healthy senescence: humans and other mammals die from senescence-associated diseases such as cancer, stroke, myocardial infarction, [etc]" (Blagosklonny, 2006a). He argues that biogerontologists often have an erroneous view of lifespan as a function of damage, and diseases of aging as relatively incidental (Figure 3A) (Blagosklonny, 2007b; Blagosklonny, 2012a). Surveying clinical literature that is typically beyond the biogerontological purview, he notes that many senescent pathologies and conditions are linked to mTOR over-activity, including cancer, atherosclerosis, hypertension, type 2 diabetes, osteoporosis, osteoarthritis, macular degeneration, and Alzheimer's and Parkinson's diseases (Blagosklonny, 2006a; Tsang et al., 2007). Thus, programmatic AP limits life by causing diseases of aging.

5.2.2. Aging as a nested series of life-limiting etiologies. A tenet of the DS theory is that aging as a whole is caused by molecular damage accumulation, suggesting that enhanced somatic maintenance could prevent aging altogether (de Grey et al., 2002; Kirkwood and Rose, 1991). There do exist organisms for which this is true: in the filamentous fungus Podospora anserina, reducing mitochondrial ROS production can prevent senescence entirely and produce a seemingly non-aging state (Dufour et al., 2000). By contrast, Blagosklonny views mTOR's impact on lifespan not as an effect on aging as a whole but rather of promotion of multiple life-limiting pathologies (or multimorbidity). He reasons that if mTOR hyperfunction were suppressed (e.g. by inhibition with rapamycin) then other disease etiologies would become more life limiting (e.g. other quasi-programs, oxidative damage, mutation, telomere shortening) (Blagosklonny, 2006a; Blagosklonny, 2007b; Blagosklonny, 2021)(Figure 3B). Similarly, de Magalhães views programmatic etiologies as a "layer of mechanisms of aging" (de Magalhães, 2012). This suggests a view of aging as a nested series of causes of senescent pathology, rather like the layers of skin in an onion: the outer skin is the life-limiting etiology (IIS/mTOR), removal of which reveals a new layer (e.g. DNA damage, perhaps) underneath (Figure 3B). Such an onion model is an implicit critique of the convention in biogerontology of viewing lifespan as a metric of aging overall; in fact, lifespan is a metric of life-limiting pathologies, which can vary with context (e.g. culture conditions, genotype, species)(Ezcurra et al., 2018; Gems and de Magalhães, 2021).

Inhibition of IIS/mTOR can increase lifespan substantially, suggesting an effect on aging as whole and, therefore, the existence of an overall aging process. An alternative view is that quasi-programs can arise independently in multiple tissues, promoting diverse senescent pathologies, all of which are supported by IIS/mTOR since they are fundamental drivers of growth and development (Figure 3C). Thus, IIS/mTOR promotes senescent multimorbidity, but not the entire aging process. This suggests that "aging as a whole" was a conceptual Fata Morgana in the minds of biogerontologists produced by a combination of IIS/mTOR inhibition effects and theories such as DS.

5.2.3. Non-cell autonomous action of quasi-programs. The idea that aging is caused by molecular damage suggests that senescence originates largely as a cell autonomous process, in which impairment of 
basic cell function leads to cell breakdown, and from there upward to tissue and organ failure. Hence, aging is a problem of cellular metabolism and cellular maintenance. By contrast, in the mTOR quasiprogram model basic cell function is in many cases unimpaired; instead, cell function is changed in a way that disrupts tissue and organismal function. Pathology results from loss of tissue, organ and physiological homeostasis rather than of cellular homeostasis. Similarly, de Magalhães observes that one can broadly divide gene function into that specifying basic cell biology (respiration, DNA replication, repair) and that specifying developmental programs, and argues that the main causes of aging are located in the latter and not, as the damage/maintenance paradigm assumes, in the former (de Magalhães and Church, 2005).

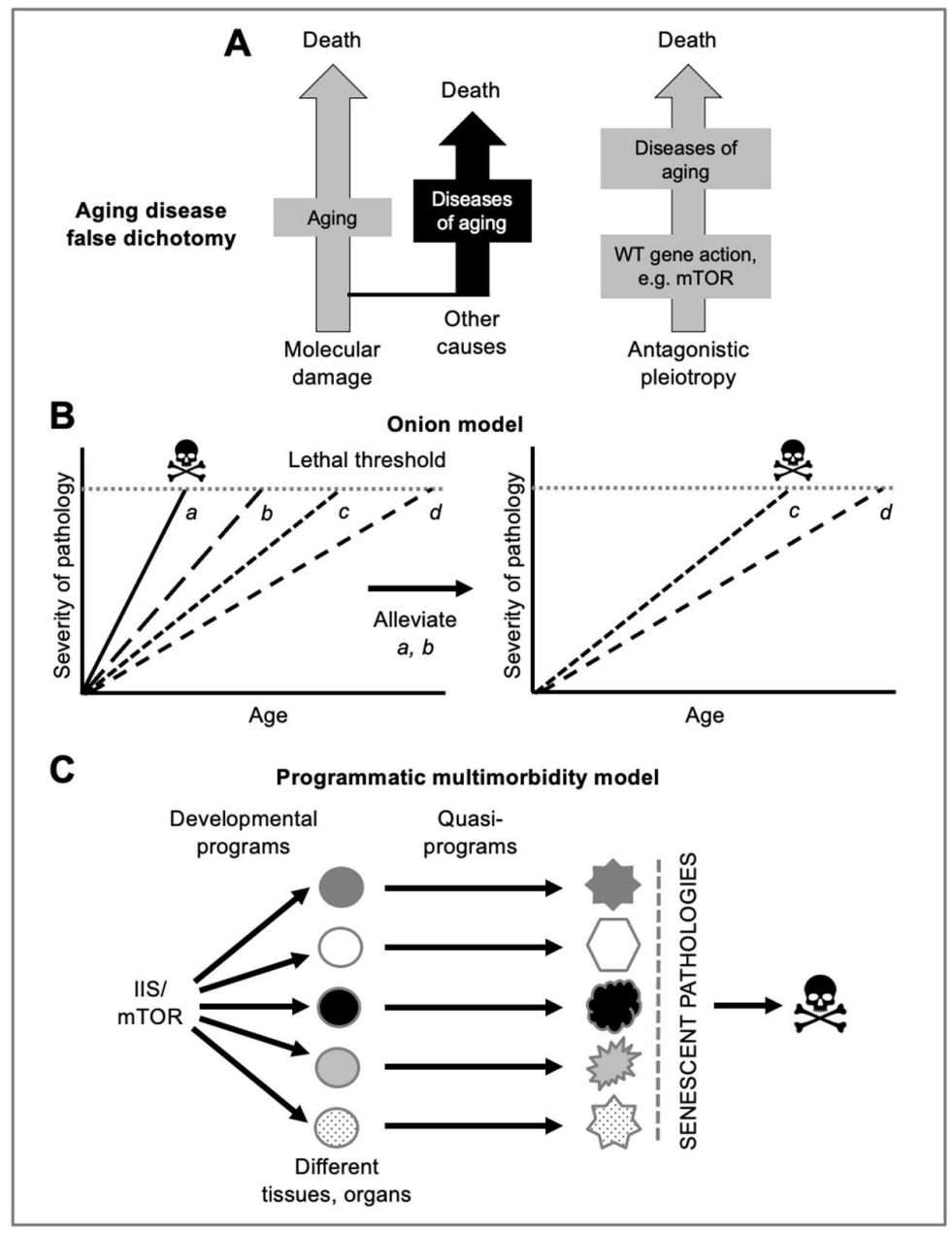

Figure 3. Concepts from the broader programmatic theory. A, The false distinction between aging and disease; adapted from (Blagosklonny, 2007b). Left, aging as a process distinct from late-life disease; here disease is incidental to understanding aging. Right, aging as diseases/pathologies caused by wildtype gene action; here disease/pathology is critical to understanding aging. Accounts of aging in terms of damage/maintenance tend to neglect the importance of disease in the aging process (Blagosklonny, 2012a; Gems and de Magalhães, 2021). B, The onion model of the relationship between aging, disease and lifespan (Blagosklonny, 2006a; de Magalhães, 2012). Lifespan is a function of one or more specific life-limiting pathologies, rather than any underlying process of aging as a whole. Left, lifespan is limited by pathology $a$. Right, a life-extending treatment acts by eliminating $a$ and $b$. Lifespan is now 
limited by pathology $c$. C, How single genes can exert large effects on aging. Growth control pathways act in diverse tissues and organs, driving diverse programs and quasi-programs, the latter leading to diverse pathologies.

Pathogenic effects of cellular hyperfunction are largely cell non-autonomous, involving hyperplasia, dysplasia, hypertrophy, hypersecretion, atrophy and cell signal resistance (see below). Blagosklonny describes how many diseases of aging are caused by hyperfunction (Blagosklonny, 2006a; Blagosklonny, 2012a; Blagosklonny, 2013d). As one example, myocardial infarction results from a combination of factors, including coronary atherosclerosis and arterial spasm, hypertension, myocardial hypertrophy and thrombosis, for each of which hyperfunction is a contributory factor. Proliferation and hypertrophy of arterial smooth muscle cells (SMC) and lipid accumulation contributes to atherosclerosis; proliferation, hypertrophy, elevated contractile function and hyper-stimulation of arterial SMC all contribute to hypertension; mTOR hyperfunction contributes to cardiac hypertrophy; and increased aggregation and adhesion of platelets contributes to increased thrombosis. An example of hyperfunction causing atrophy is progression of osteoporosis due to osteoclast hyperactivity, which is promoted by mTOR (Blagosklonny, 2006a). Thus, the pathogenic effects of hyperfunction in the main do not work from bottom up, by harming individual cells that exhibit it; instead, hyperfunctional cells are robust and, in themselves, healthy, even though they might be damaged (as in cancer cells) (Blagosklonny, 2008b; Blagosklonny, 2012a). Instead, hyperfunctional cells cause pathology at the tissue and organ level. However, one noxious cell-autonomous effect of mTOR hyperfunction is reduced autophagic clearance of aggregation-prone proteins, increasing risk of several age-related neurodegenerative diseases (Blagosklonny, 2006a).

If pathogenic effects of cellular hyperfunction are largely cell non-autonomous, then what about aging in single cell organisms? Notably, in budding yeast (Saccharomyces cerevisiae) inhibition of TOR can increase lifespan (Blagosklonny and Hall, 2009), implying that TOR promotes cell death in this species. Blagosklonny suggests that aging in bacteria results from damage accumulation (Blagosklonny, 2012a), and presumably this applies to unicellular eukaryotes too.

5.2.4. Programmatic etiologies as a target for intervention. This new model provides an account of rapamycin action against aging. Quasiprograms occur due to the late-life selection shadow, which has resulted in insufficient off switches (Williams, 1957); rapamycin in later life can rectify some of this insufficiency (Blagosklonny, 2006a). More broadly, the model predicts a general preventative approach to age-related disease: to allow enactment of programs but, in later life, inhibit quasiprograms. This possibility is implicit in Williams' calcium gene scenario: one could imagine a treatment to prevent it from promoting vascular calcification in later life.

Validating anti-aging drugs requires biomarkers of aging, the search for which has been a long-standing objective in aging research. This includes a major program by the US National Institute on Aging initiated in 1988 to try to identify biomarkers of aging in rodents (Warner, 2004). Since aging is a developmentally-driven multimorbidity (rather than a metabolic problem within cells), then a good biomarker is progression of multiple diseases of aging (Blagosklonny, 2009b). Potential anti-aging drugs can be identified through re-analysis of 
outcomes of drug tests against individual diseases, to look for wider antidisease effects. For example, rapamycin administered to renal transplant patients unexpectedly reduced cancer rates in several studies (Blagosklonny, 2009b). This principle implies that obesity accelerates aging, since it increases the rates of multiple aging-related diseases (Blagosklonny, 2011b), meaning that reducing obesity is an anti-aging treatment.

5.2.5. Pathogenic effects of mTOR acting as a brake on growth. A recurrent theme in Blagosklonny's thinking is that mTOR is a driver of growth that becomes pathogenic when growth has to cease (Figure 4A). mTOR itself can act as a brake on growth by cutting off upstream growth-promoting signals via feedback inhibition. Specifically, mTOR acts through S6 kinase to inhibit IRS-1 (insulin receptor substrate) (Figure 4B), leading to receptor signal resistance, including insulin resistance that contributes to type 2 diabetes (Blagosklonny, 2006a). Signal resistance caused by mTOR may also contribute to age-related loss of stem cell function (Blagosklonny, 2008a).

Blagosklonny views mTOR within the cell as a microcosm at the cellular level of homeostatic function at the organismal level, particularly in the hypothalamus, where pathology also develops due to signal resistance (Blagosklonny, 2013b; Dilman, 1971). As he points out, like the hypothalamus, mTOR integrates diverse signals, in the latter from insulin, mitogens, cytokines, oxygen, and nutrients (Figure 4B). The recurrence of AP behavior of mTOR suggests the presence of a trade-off between the risks of allowing vs preventing growth that hinges on mTOR activity. The idea that a brake on growth at the end of ontogenesis causes aging was proposed previously, in a different context (Bidder, 1932).

Blagosklonny also emphasizes that cellular senescence occurs as a pathogenic consequence of mitogenic signals acting when cell cycle progression is blocked, leading to mTOR-driven geroconversion to the hypertrophic, hypersecretory state (Blagosklonny, 2003a; Blagosklonny, 2006a; Blagosklonny, 2006b; Blagosklonny, 2009a; Blagosklonny, 2011a; Blagosklonny, 2012b; Blagosklonny, 2014a; Blagosklonny, 2018b). However, cellular senescence as a quasi-programmed, non-adaptive abnormality occurring during aging is, one assumes, distinct from programmed, adaptive cellular senescence with functional utility in embryogenesis or wound healing (Demaria et al., 2014; Munoz-Espin and Serrano, 2014). The importance of mTOR in both cases suggests that adaptive cellular senescence could have evolved by exaptation (acquisition of a new function by an existing feature) (Gould and Vrba, 1982) from a non-adaptive, purely pathological ancestor (Figure 4C).

5.2.6. Programmatic loosening as a feature of aging. According to programmatic theory, the processes of development and aging unfold as the result of shared developmental mechanisms. But compared to development proper, aging is far more variable and, seemingly, disordered. Development is a highly precise, stereotyped process. By contrast, each person's individual experience of aging is unique; one starts with lower backpain and shingles, and progresses to macular degeneration and death from colon cancer, while another starts with osteoarthritis in the fingers and urge incontinence, and moves on to vascular dementia and an eventual lethal stroke. To some extent this variation will reflect differences in genotype and environment. The importance of factors other than genetic difference is illustrated by the 
considerable degree of discordance even between monozygotic twins in terms of diseases of aging, $~ 50 \%$ for type 2 diabetes, for example (Poulsen et al., 1999). Even in C. elegans where population cohorts of genetically identical individuals can be maintained in the same Petri dish, the lifespans of individual nematodes vary greatly (from 10-30 days under standard culture conditions), and different causes of death can be observed (Rea et al., 2005; Zhao et al., 2017).

Variability in outcome would seem to be an inherent property of the aging process. Blagosklonny argues that variability of outcome is a characteristic feature of quasi-programs: "As an unintended continuation of the developmental program, the quasi-program is not very precise" (Blagosklonny, 2007b). Consistent with this, chronological age is a good surrogate for biological age (as estimated using a methylation clock, DNAm age, described below) during development but increasingly less so in later life (Horvath and Raj, 2018). Moreover, gene expression heterogeneity remains low during development but increases during aging (Iş̧ldak et al., 2020). The authors of this study interpreted this as evidence that stochastic rather than developmental processes contribute to aging; an alternative interpretation is that such heterogeneity reflects developmental stochasticity characteristic of quasi-programs.

The progressive developmental loosening associated with quasi-programs may result from the age decline in natural selection. In earlier life greater selection maintains the precision of developmental programs, but it wanes with increasing age, this precision declines. A formal possibility is that genetic determinants of precision are subject to antagonistic pleiotropy involving trade-offs between earlier developmental precision and later precision loss.

In summary, the programmatic theory defines an etiological principle that contributes to many diseases of aging. Wild-type gene action promotes pathogenic quasi-programs in later life, in line with Williams' original conception of AP. Promotion of quasi-programs by wild-type levels of IIS/mTOR can at least partially explain how they accelerate aging. This conceptual framework also provides a principle for treatment (inhibition of quasi-programs), actual possible treatments (e.g. mTOR inhibitors), and approaches to test them experimentally in humans.

\subsection{Blagosklonny on the attack}

In many of his essays, Blagosklonny uses conceptual research to compare how well damage-based and programmatic theories do at explaining findings past and present. Overall, these find in favor of the latter, and support critiques of many traditional biogerontological claims and concepts, which he sometimes pokes fun at for their perceived inadequacies.

5.3.1. Against the oxidative damage theory. The theory that molecular damage caused by ROS causes aging dominated biogerontology from the 1980s to the mid-2000s. The wide net of Blagosklonny's conceptual research led him to conclude that scientific evidence does not generally support the ROS theory (Blagosklonny, 2006a; Blagosklonny, 2008b), a suspicion shared by de Magalhães and I (de Magalhães, 2005; Keaney and Gems, 2003; Keaney et al., 2004). The crisis in the ROS theory that culminated in 2008-09 has been reviewed extensively elsewhere (Gems and Doonan, 2009; Perez et al., 2009; Shields et al., 2021; Van Raamsdonk and Hekimi, 2010). It is true that there is a correlation 
between aging and accumulation of molecular damage. Of this, Blagosklonny says: "With age, I have accumulated a considerable knowledge regarding the ROS theory. Does this knowledge cause my aging? I hope not" (Blagosklonny, 2008b). Instead, he argues that damage accumulation is symptomatic of later stages of diseases of aging caused by hyperfunction.

5.3.2. Against disposable soma. The mTOR-driven quasi-programs (mTOR/QP) model provides an alternative ultimate-proximate model to the disposable soma (DS) theory, that is closer to Williams' own original idea about proximate mechanisms of AP. Blagosklonny even refers to this model as "disposable soma theory 2", insofar as the soma is disposable as the result of $\mathrm{mTOR} / \mathrm{QP}$ action (rather than resource allocation etc) due to AP and the later-life selection shadow (Blagosklonny, 2013c). He points out that the mTOR/QP model originates from consideration of diverse scientific findings, unlike either Harman's free radical theory (Blagosklonny, 2008b) or the DS theory (Blagosklonny, 2010e), and argues that it outperforms DS at explaining a range of phenomena.

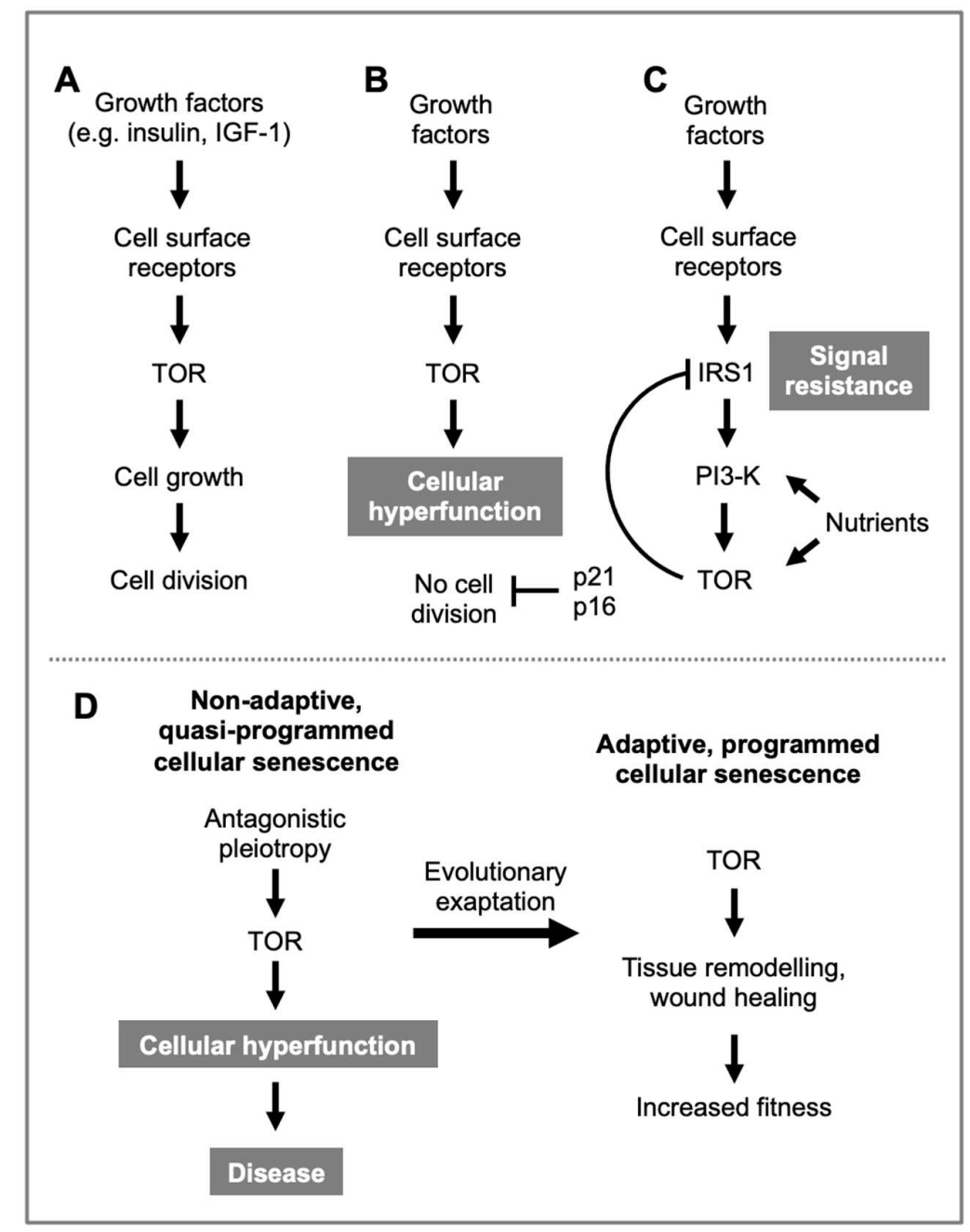

Figure 5. TOR in cellular senescence: evolutionary and mechanistic perspectives (Blagosklonny, 2006a). A, During development, cell growth and cell division occur in concert, leading to constant average cell size. B, When the cell cycle stops due to CDK inhibitor action, TOR stimulation continues and becomes 
hyperfunctional. C, Negative feedback inhibition of TOR occurs by phosphoinhibition of IRS1 (insulin receptor substrate 1) by the TOR effector S6 kinase; PI3-K, phosphoinositide 3-kinase. This reduces TOR hyperfunctionality by promoting signal resistance, which in turn can have pathogenic effects (e.g. insulin resistance, leading to type 2 diabetes). D, Evolution of adaptive, programmed cellular senescence by exaptation from non-adaptive quasiprogrammed cellular senescence (hypothetical scheme). Most cellular senescence is pathogenic, caused ultimately by AP. But some forms of cellular senescence have evolved a function, as in wound healing promoted by senescent fibroblasts (Demaria et al., 2014). In the context of adaptive cellular senescence, the term "senescence" is illogical.

For example, the life-extending effects of dietary restriction (DR) have been reconciled with DS by the allocation hypothesis. Here it is argued that DR leads to diversion of resources from reproduction to somatic maintenance, thereby increasing lifespan (Holliday, 1989; Kirkwood and Shanley, 2005; Masoro and Austad, 1996)(Figure 5A). Blagosklonny argues that this is implausible for a number of reasons. Perhaps most cogently, a more parsimonious prediction from DS is that increasing resources for somatic maintenance would increase lifespan and vice versa (Blagosklonny, 2007b). By contrast the mTOR/QP model argues simply that reduction in nutrients reduces mTOR activity, which suppresses both growth and QPs (Figure 5B).

As another example, inhibition of protein biosynthetic genes in C. elegans increases lifespan, and it was suggested that this is due to freeing up of resources that are then invested in somatic maintenance (Hansen et al., 2007; Hipkiss, 2007). Blagosklonny argues instead that reducing protein synthesis prevents QP progression, pointing out that mTOR promotes protein synthesis (Blagosklonny, 2007b). As a third example, it was argued from the DS theory that women live longer due to increased investment into somatic maintenance (Kirkwood, 2010). Blagosklonny reasons that DS predicts that women should live shorter, since they invest more into reproduction; he suggests instead that increased mTOR activity promotes muscle growth in males, but accelerates aging (Blagosklonny, 2010a; Blagosklonny, 2010d; Leontieva et al., 2012b).

5.3.3. Against stress-response hormesis. For some toxins, a lower dose range exists that promotes health (e.g. increased growth rate, stress resistance), an effect known as hormesis (Calabrese et al., 1999). In some cases this occurs due to induced expression of cytoprotective genes, so called stress-response hormesis (Gems and Partridge, 2008). For example, sub-lethal heat stress induces a heat shock response that can protect $C$. elegans against subsequent heat stress that would otherwise be lethal (Lithgow et al., 1995). Treatments that chronically increase ROS levels can increase C. elegans lifespan (Schulz et al., 2007; Yang and Hekimi, 2010), seemingly a challenge to the ROS theory. However, it has been suggested that this could reflect hormesis, where induction of antioxidant defences by ROS protects against aging caused by ROS; this includes ROS production by mitochondria inducing mitohormesis (Radak et al., 2005; Ristow and Zarse, 2010). Blagosklonny sees this account as an attempt to rescue the ROS theory from findings that contradict it, and sends up its logical awkwardness (increasing ROS reduces ROS). He compares it to Baron Munchausen's adventure when, falling into a swamp, he escapes by pulling himself up by his own hair (Blagosklonny, 2008b). He suggests instead that effects of stress on 
lifespan more plausibly result from inhibition of growth processes that drive both development and quasi-programs (Blagosklonny, 2007b).

A constraint to progress in biogerontology is the everincreasing volume of research output, which means it is difficult for researchers to keep abreast of the whole field. For this reason, the conceptual research approach is timely. By using it Blagosklonny has been able to develop a coherent and empirically well-supported framework of understanding of many aspects of the biology of aging. Yet it by no means presents a full picture of the process of aging, nor does it pretend to.

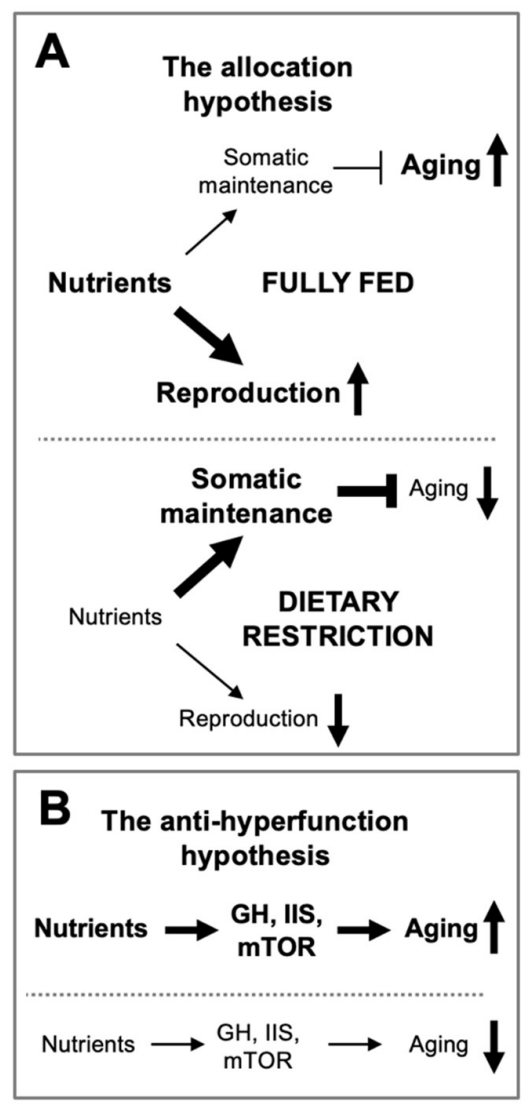

Figure 5. Alternative theories about how dietary restriction increases lifespan. A, The allocation hypothesis, based on the disposable soma theory. Reduced food leads to increased investment in somatic maintenance. B, Explanation based on the hyperfunction theory. Here reduced nutrients reduces growth pathway signaling, thus reducing quasi-programmed hyperfunction. Figure redrawn from (Blagosklonny, 2007b). The latter is both more parsimonious and consistent with existing knowledge of pathophysiology of various diseases of aging.

\section{João Pedro de Magalhães}

The programmatic theory reconciles a mechanistic theory based on developmental change with the AP theory, and provides an account of IIS/mTOR action on aging. But both developmental changes during aging, and AP are wider phenomena, as has been emphasized (Maklakov and Chapman, 2019), and all causes of aging is a wider category still. de Magalhães, originally from Portugal and now at the University of Liverpool, gives some consideration to programmatic etiologies in the broader sense (de Magalhães and Church, 2005), and explores issues 
relating to the programmatic theory that Blagosklonny touches on more briefly or not at all, including the following. How does the programmatic theory relate to earlier developmental theories of aging? And: how does it relate to epigenetic changes during adulthood?

\subsection{From developmental theories to the programmatic theory}

Over the years it has often been suggested that aging is a form of developmental abnormality, resulting e.g. from increased or decreased gene silencing, transcriptional deregulation, dysdifferentiation or overdifferentiation (de Magalhães and Church, 2005). Certain broad characteristics of aging are suggestive of its developmental nature. For example, different mammals (e.g. mice vs humans) differ greatly in terms of rate of development, timing of maturity, and of appearance of many of the same diseases of aging (e.g. cancer, osteoporosis, cataracts) (de Magalhães and Church, 2005). This is also true of the gradual agedependent decline in cognitive function (De Magalhaes and Sandberg, 2005). Moreover, across mammalian species the ratio between time from conception to sexual maturity and adult lifespan is approximately constant, at about 1:4 (Charnov, 1993), suggesting a possible mechanistic relationship between development rate and adult lifespan (de Magalhães and Church, 2005). Similarly, the complex and stereotyped nature of many manifestations of senescence (e.g. atherosclerosis, osteoporosis, male pattern baldness) seem more consistent with programmatic pathophysiology than random molecular damage (Blagosklonny, 2006a).

While it is clear that both stochastic damage and programmatic changes contribute to senescence, in terms of their relative importance these are competing theories. The former predominated during recent decades, but less so prior to that. For example, as de Magalhães points out (de Magalhães, 2012), the discovery of effects of DR on aging, initially in fruit flies and rats, arose from the idea that slow growth rate results in slower aging (McCay and Crowell, 1934; Northrop, 1917; Osborne et al., 1917; Park, 2010), including Bidder's hypothesis (Bidder, 1932). Later work showing that although life-long DR limits growth, adult-limited DR was sufficient to extend lifespan in fully grown mice (Weindruch and Walford, 1982) appeared to argue against the developmental theory; however, it is consistent with stunting of quasiprograms during adulthood.

Similarly, in chico (insulin receptor substrate) mutant fruit flies with reduced IIS, increased lifespan is seen in both chico homozygotes and heterozygotes, but only the homozygotes exhibit reduced body size (Clancy et al., 2001; Tu et al., 2002). Thus, chico mutant longevity is not caused by their reduced body size (Gems and Partridge, 2001), suggesting that reduced growth does not slow aging; however, these results, again, do not rule out suppression of quasi-programs during adulthood. In fact, chico $^{-/+}$heterozygote females show reduced egg production (Clancy et al., 2001), consistent with biosynthetic (and programmatic) insufficiency.

Arguably, the confusion here stems partly from ambiguities arising from the words growth and development. Simply understood these refer to changes occurring during ontogenesis that largely cease at sexual maturity. A metric of growth is adult body size, and to speak of growth after maturation in organisms with determinate growth, after they have stopped growing, makes little sense. But in the programmatic model, growth pathways promote quasi-program progression, or "twisted growth" as it has been described (Blagosklonny, 2008b) during 
adulthood. Similarly, development. A quasi-program is defined as "a program for development that has not been turned off" (Blagosklonny, 2006a). Yet it is clear that what is meant here is development in the sense of all complex programs involving growth and differentiative change: not only those of ontogenesis, but also for example those involved in reproduction and tissue repair and remodelling during adulthood (c.f. the role of "senescent" fibroblasts in wound healing) (Demaria et al., 2014). To avoid this confusion the term programmatic theory is used here, rather than developmental theory as previously (Maklakov and Chapman, 2019). This avoids confusion with earlier developmental theories of aging, and over the meaning of development, and also alludes to the reconciliation of ultimate and proximate perspectives in the theory.

\subsection{From the programmatic theory to epigenetic aging and biological clocks}

A recent topic of interest among biogerontologists has been epigenetic changes during adulthood (Benayoun et al., 2015; Horvath and Raj, 2018). de Magalhães notes studies showing similarities between changes in gene expression occurring during development and aging (Lui et al., 2010; Somel et al., 2010; Takasugi, 2011) as evidence that drivers of epigenetic change are programmatic rather than stochastic (de Magalhães, 2012). As a developmental process, quasi-program execution is expected to involve epigenetic change. Thus, the programmatic theory provides an explanation in terms of ultimate and proximate causes for epigenetic changes in aging (though this does not rule out the action of other contributory mechanisms).

The question of how biological time is marked during aging is central to biogerontology, and many forms of clock have been proposed. These include a metabolic clock in the rate-of-living theory (Pearl, 1928), a telomere shortening replicometer in replicative senescence (Olovnikov, 1996), and epigenetic changes such as DNA methylation (Horvath, 2013; Horvath and Raj, 2018). According to the programmatic theory, the major aging clock is a developmental one. de Magalhães sees epigenetic changes as likely to arise from the ticking of a developmental clock (de Magalhães, 2012), whose speed is increased by IIS/mTOR (de Magalhães and Church, 2005). Consistent with this, the methylation clock is slowed by conditions in which mTOR is inhibited (Blagosklonny, 2018a), for example in mice treated with rapamycin, in long-lived Ames (Prop1), Snell (Pit1), and Laron (Ghr) dwarf mutant mice with defective GH signaling (Cole et al., 2017; Consortium, 2021; Petkovich et al., 2017; Wang et al., 2017), and in rapamycin-treated cultured human fibroblasts and keratinocytes (Horvath et al., 2019; Matsuyama et al., 2019). Moreover, mTOR functions in circadian clocks, underscoring the role of mTOR in setting the pace of biological time (Blagosklonny, 2018a).

The developmental basis of epigenetic changes during adulthood in mammals has received further support from recent work by Steve Horvath and colleagues. Of particular note, methylation clocks mark time during embryogenesis and postnatal development as well as (running much more slowly) during adulthood, and clock methylation sites are strongly associated with genes specifying developmental processes. The latter include those under regulation of the polycomb repressor complex (PRC), including multiple Hox genes, leading to the conclusion that "the essence of the aging process itself is an integral part of, and the consequence of the development of life" (Raj and Horvath, 2020). The link between clock methylation sites and PRC-regulated genes was also recently seen in a universal mammalian methylation clock, 
implying evolutionary conservation of developmental clock mechanisms (Consortium, 2021).

Almost a century ago, Raymond Pearl attributed rate-ofliving effects, as seen in effects of ambient temperature on lifespan in poikilotherms (e.g. Drosophila, C. elegans)(Klass, 1977; Loeb and Northrop, 1917) to metabolic rate (Pearl, 1928), an idea that was subsequently linked to the ROS theory (Sohal and Weindruch, 1996). The programmatic theory suggests instead that effects of temperature on both development and aging reflects a change in the rate of developmental processes.

\section{Vladimir Dilman: programmatic aging within a multifactorial model}

As emphasized in the opening of this essay, antagonistic pleiotropy and programmatic mechanisms are clearly not the sole cause of aging. To close, I will present a sketch of a model of the whole aging process, derived from a scheme originally developed in the 1980s by Vladimir Dilman, but modified here in the light of recent advances. Dilman, who died in 1994, was a preeminent gerontologist and clinician in the U.S.S.R., in many ways the Soviet Union's equivalent to thoughtful biogerontologists in the West such as Alex Comfort, Bernard Strehler, Richard Cutler and Caleb Finch, but his theories are little known outside Russia. He was also the father of Misha Blagosklonny.

\subsection{Dilman's ontogenetic and four models theories}

Dilman argues that, overall, aging and age-related disease are etiologically multifactorial, and attributable to four distinct disease models: ecological, genetic, accumulational and ontogenetic (Dilman, 1994) (Chapter 11) (Figure 6A). Ecological here is in the sense used by Frederic Ludwig to describe the main disease model in medicine, where diseases result from harmful extrinsic factors ranging from infectious pathogens to dietary toxins (Ludwig, 1980). Genetic here refers to inherited genetic diseases, rather than somatic mutations or pathogenic action of wild-type genes. The accumulational model includes molecular damage accumulation, but also other types of pathogenic accumulative processes. The ontogenetic model involves the continued action of developmental processes in later life promoting senescence.

According to this four models scheme, mean lifespan and inter-individual variation in lifespan is largely attributable to ecological and genetic determinants, and maximum lifespan to accumulational and, particularly, ontogenetic determinants. While Dilman's ontogenetic model clearly prefigures the programmatic theory, it was derived as a generalization from a now partially outdated theory about the control of aging by the hypothalamus. Briefly, this argued that aging is largely caused by programmed loss of hypothalamic sensitivity to feedback inhibition, leading to compensatory endocrine changes with pathogenic consequences, what he called hyperadaptosis (Dilman, 1984). The ontogenetic processes that he particularly refers to are those controlling systemic homeostasis in adulthood, namely energy metabolism (insulin), reproduction (estrogen) and adaptive systems (glucocorticoids).

Yet in amongst Dilman's many ideas and reflections are key elements of the new programmatic theory, including the following. The ontogenetic model itself is prescient; as Dilman describes it: "the genetic program of an organism is not constructed according to the rule 'from beginning to end,' but proceeds 'from a beginning, with the end unspecified"' (Dilman, 1994)(Chapter 6). He notes in passing the 
congruence between the ontogenetic model and antagonistic pleiotropy (Dilman, 1986). Like Blagosklonny, he emphatically rejects the distinction drawn between normal aging and age-related disease: "normal aging is a disease, or more precisely, a sum of diseases" (Dilman, 1994)(Chapter 6). Like de Magalhães, he emphasizes that ontogenetic etiologies are operative at a level above that of the cellular; however, he views the key level as systemic, while in the modern programmatic theory it is at all supra-cellular levels (from tissue microenvironment to systemic). By contrast, at the subcellular level, accumulative mechanisms are more important (e.g. DNA damage accumulation).

Again like de Magalhães, he views the fixity among mammals of the length of the developmental period as a proportion of total lifespan as support for the role of ontogenetic mechanisms in aging. Here he makes an interesting observation. The standard explanation for this constancy is that an increased selection shadow (e.g. due to increased extrinsic mortality) leads to the evolution of earlier sexual maturity and shorter lifespan, via independent mechanisms (earlier reproduction increases fitness, earlier selection shadow allows earlier senescence to evolve) (Charnov, 1993; Harvey and Purvis, 1999; Promislow, 1993). But Dilman wonders about the obverse situation, where longevity evolves to increase fitness via a longer reproductive span. He asks: given the independent mechanisms model, why should a delay in sexual maturity occur? More plausibly, longevity evolves through deceleration of the entire ontogenetic program, which slows both development and aging (Dilman, 1994)(Chapter 11); Blagosklonny later made a similar point (Blagosklonny, 2013a). According to this interpretation, the longer development time in humans relative to other higher primates evolved not due to any fitness benefit, but as a side-effect of selection for increased longevity, i.e. it is an unselected outcome of antagonistic pleiotropy, an evolutionary spandrel (Gould, 1997; Gould and Lewontin, 1979). Consistent with the ontogenetic model is the earlier puberty, accelerated cognitive decline and shorter lifespan in mice over-expressing growth hormone, and the converse effects in dwarf and DR mice (Chandrashekar et al., 2004).

A major question raised by multifactorial models of aging is how the component factors interact with one another and here Dilman is, again, insightful. He argues that both ecological and accumulative factors can modulate ontogenetic aging, and that accumulational and ontogenetic mechanisms, though fundamentally independent are yet interwoven. He also suggests that stochastic damage may occur either in a wholly probabilistic fashion (as in somatic DNA damage accumulation), or as the result of genetically-determined programmatic mechanisms, what he refers to as "regular stochastic processes". Here he has in mind ROS generated by mitochondrial metabolism. A recent case fitting this description is protein aggregation in C. elegans, resulting from a programmatic down-regulation of proteostatic mechanisms from around the time of sexual maturation (Labbadia and Morimoto, 2014).

\subsection{A new multifactorial model based on Dilman's four models}

While Dilman's ontogenetic theory is a predecessor of the programmatic theory, one can, in a rather recursive fashion, modify and update his four models theory in the light of its newer descendent (Figure $6 \mathrm{~B})$. First, by acknowledging the predominance of the wild-type genotype as the determinant and driver of programmatic mechanisms. This incorporates AP as a major determinative mechanism. Second, to unify 
ecological and genetic determinants into a single, broad category of causes apart from wild-type function. These represent the major causes of diseases in earlier life, where normal, wild-type function is disrupted. The rearranged scheme emphasizes the centrality of wild-type function, which can be illustrated by a thought experiment. If ecological and genetic factors were, by magic, eliminated, aging would still occur, and there would be little change in either the rate of acceleration of mortality with age (Gompertzian aging) or maximum lifespan. By contrast, if mechanisms of aging from wild-type function were removed, Gompertzian aging would be greatly reduced, though not, one assumes, entirely, due to accumulative mechanisms independent of wild-type function.
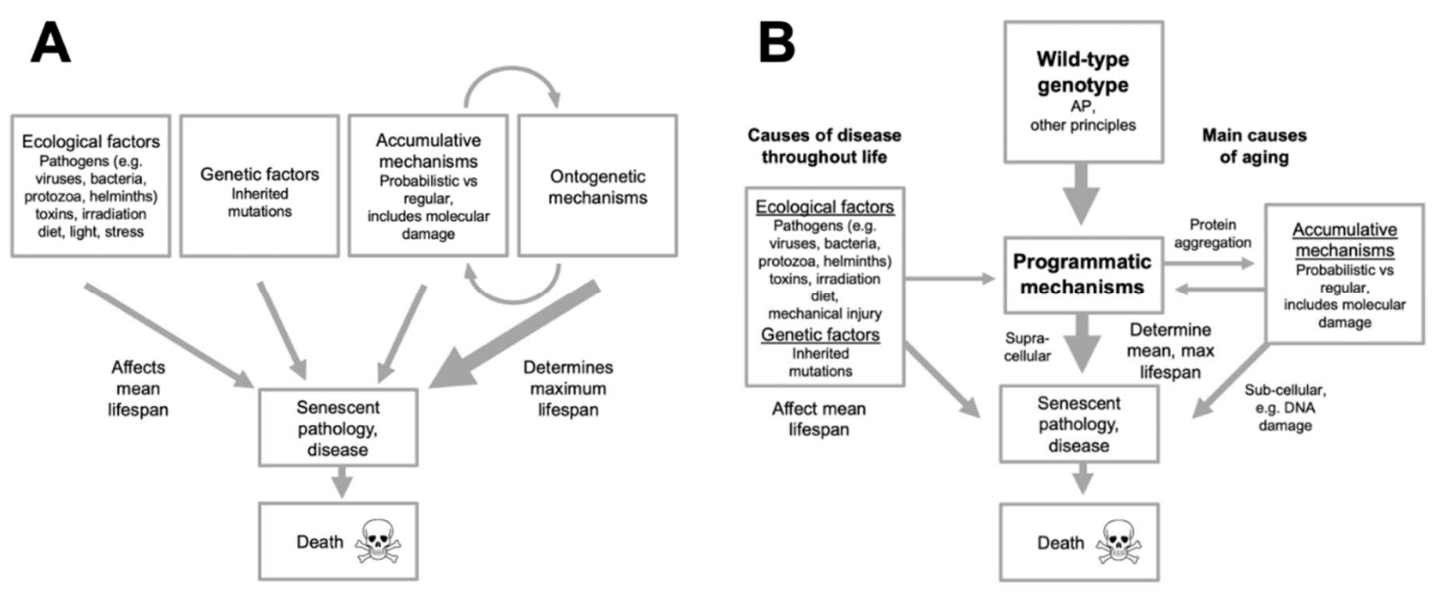

Figure 6. The bigger picture. Multifactorial models, in which programmatic AP is a single element. A, Dilman's four models mechanism. This representation is based on his account, but leaves out his hypothalamic threshold model (Dilman, 1994). Here the major determinant of aging and mean and, particularly, maximum lifespan is ontogenetic mechanisms, with accumulative mechanisms (e.g. molecular damage accumulation) playing a lesser role. Ecological (i.e. extrinsic) and genetic determinants contribute to senescent pathology, and are a major determinant of mean lifespan, and variation in individual lifespan. B, Dilman's multifactorial model rearranged, to incorporate more recent ideas. Here the major determinant of programmatic (ontogenetic) senescence is wildtype genotype, including pathogenic wild-type gene action due to antagonistic pleiotropy. But genotype-specified programmatic mechanisms contributing to aging clearly involve more than AP (Maklakov and Chapman, 2019). The model makes clear the centrality of wild-type function in aging. Even in the absence of other factors (ecological, genetic), senescence will occur, and maximum lifespan will change little. Factors that contribute to disease throughout life and do not reflect wild-type function, both extrinsic (ecological) and intrinsic (mutation) are grouped into one broad category. Included here is mechanical damage (mechanical senescence), not included by Dilman. One determinant not shown is the effect of extrinsic factors on damage accumulation (e.g. skin damage due to solar UV radiation). .

The role of inherited mutations in aging in this model requires further explanation. One proposed cause of aging, and mechanism of its evolution, is inherited mutations whose deleterious effects are expressed only later in life, as exemplified by Huntington's disease (Haldane, 1941; Medawar, 1952). An unexplained feature of this mutation accumulation theory is the mechanism that causes a mutation to remain harmless throughout development and early adulthood, and then become harmful 
in later life. One possibility is that it is wild-type gene action and programmatic changes that cause the deleterious effects of such mutations to become expressed, or unmasked. Returning to the thought experiment again: according to the unmasking hypothesis, if one eliminated the wild-type gene action component from the revised Dilman model (Figure 6B), a carrier of the Huntington mutation would not develop the disease.

An important feature of multifactorial models of aging, noted previously (Ezcurra et al., 2018; Gems and de Magalhães, 2021), is their highly context-dependent nature. For a given animal species, the relative contribution of different etiological factors will vary not only between different elements of senescence (e.g. different diseases of aging), but also between individuals. Moreover, the relative contribution of different factors may vary more broadly between species. For example, in humans, environmental, genetic, ontogenetic and accumulative factors all contribute to the development of atherosclerosis, a major determinant of age-related death in humans. The relative importance of these factors will vary between individuals. In one, a major cause may be obesity, and increased cholesterol accumulation; in another, genetic predisposition (e.g. the ApoE4 mutation), in a third, wild-type gene action may act alone. By contrast, the large uterine tumors that are invariably present in senescent $C$. elegans develop due to wholly programmatic mechanisms (Wang et al., 2018a; Wang et al., 2018b), consistent with the view that plastic, programmatic mechanisms play an exceptionally large role in aging in C. elegans (Gems et al., 2021; Lohr et al., 2019).

\subsection{The ontogenesis of the programmatic theory}

Scientific discovery is rightly the object of wonder, something to marvel at. In my view, this applies to the programmatic theory. In the early 18th century a fierce priority dispute broke out between Isaac Newton and Gottfried Leibniz arguing over who invented calculus. The modern view is that this was silly, and that both men developed it independently. Such independent, simultaneous discoveries are quite common, and illustrate how scientific innovation is not so much a reflection of individual genius, as interactions of imaginative individuals with a collective and evolving fabric of knowledge. Once the fashion among scientists, these days I-said-it-first-ism risks being interpreted as a character weakness (principally, egotism).

The transpersonal nature of scientific thinking applies well to the programmatic theory, which has evolved over a long period, with certain key contributors. Dilman's overall scheme, based around his hypothalamic model, was flawed and did not cohere well, yet included a number of prescient elements which contributed to Blagosklonny's more compelling and better-supported theorem. Dilman himself noted similarities between his ontogenetic theory and Bidder's hypothesis, formulated in the 1930s (Dilman, 1986). By contrast, de Magalhães' version of the programmatic theory was developed without knowledge of either Dilman or Blagosklonny's work. The possibility of the programmatic theory was, as it were, hanging in the air from the early 2000s, and both de Magalhães and Blagosklonny spotted it, with Blagosklonny developing it in more detail with respect to its capacity to explain the origins of disease. Yet the programmatic theory of the mid2000s forms only part of a wider biology of aging, as discussed here and elsewhere (Galimov and Gems, 2021; Gems et al., 2021; Lohr et al., 2019; Maklakov and Chapman, 2019). Of Dilman: he was in many ways ahead 
of his time and his work deserves greater recognition than it received during his lifetime (at least, outside Russia). He was noted for his creative and integrative thinking style (Napalkov, 2001), characteristics shared by Blagosklonny, and de Magalhães too.

\section{Concluding remarks}

The programmatic theory of aging as developed by Blagosklonny and de Magalhães promises to eventually serve as part of a general framework of understanding aging and the pathophysiology of late-life disease. This could at long last provide the field of biogerontology with an effective explanatory paradigm similar to that provided by the germ theory for the study of infectious disease, and the periodic table for chemistry. More work is needed to explore, test and expand this framework of ideas. This includes elements not discussed here, which will be the subjects of future essays, such as the concept of hypofunction (Maklakov and Chapman, 2019), biological constraint, how quasiprograms are initiated, and how quasi-programs interact in disease pathophysiology.

Acknowledgments: The author thanks M.V. Blagosklonny, C.C. Kern, E.R. Galimov, J.P. de Magalhães, A.A. Maklakov and D.H. Nussey for useful discussion and/or comments on the manuscript. This work was supported by a Wellcome Trust Investigator Award (215574/Z/19/Z) to D.G.. For the purpose of Open Access, the author has applied a CC BY public copyright licence to any Author Accepted Manuscript version arising from this submission.

\section{References}

Abrams, P., 1993. Does increased mortality favor the evolution of more rapid senescence? Evolution. $47,877-887$.

Armstrong, S., 2019. What is ageing?, Borrowed Time: The Science of How and Why We Age. Bloomsbury Sigma, London, pp. 15-28.

Austad, S.N., 2004. Is aging programed? Aging Cell. 3, 249-251.

Beckman, K.B. and Ames, B.N., 1998. The free radical theory of aging matures. Physiol. Rev. 78, 547581.

Benayoun, B., Pollina, E. and Brunet, A., 2015. Epigenetic regulation of ageing: linking environmental inputs to genomic stability. Nat. Rev. Mol. Cell. Biol. 16, 593-610.

Bidder, G.P., 1932. Senescence. Br. Med. J. 2, 583-585.

Bjelakovic, G., Nikolova, D., Gluud, L.L., Simonetti, R.G. and Gluud, C., 2007. Mortality in randomized trials of antioxidant supplements for primary and secondary prevention: systematic review and meta-analysis. JAMA. 297, 842-857.

Blagosklonny, M.V., 2003a. Cell senescence and hypermitogenic arrest. EMBO Rep. 4, 358-362.

Blagosklonny, M.V., 2003b. Conceptual research and phenomenology - harmonizing slices. Cell Cycle. 2, 3-4.

Blagosklonny, M.V., 2005a. Carcinogenesis, cancer therapy and chemoprevention. Cell Death Differ. $12,592-602$.

Blagosklonny, M.V., 2005b. How cancer could be cured by 2015. Cell Cycle. 4, 269-278.

Blagosklonny, M.V., 2005c. Molecular theory of cancer. Cancer Biol. Ther. 4, 621-627.

Blagosklonny, M.V., 2006a. Aging and immortality: quasi-programmed senescence and its pharmacologic inhibition. Cell Cycle. 5, 2087-2102.

Blagosklonny, M.V., 2006b. Cell senescence: hypertrophic arrest beyond the restriction point. J. Cell. Physiol. 209, 592-597.

Blagosklonny, M.V., 2007a. An anti-aging drug today: from senescence-promoting genes to antiaging pill. Drug Discov. Today. 12, 218-224.

Blagosklonny, M.V., 2007b. Paradoxes of aging. Cell Cycle. 6, 2997-3003.

Blagosklonny, M.V., 2007c. Program-like aging and mitochondria: instead of random damage by free radicals. J. Cell. Biochem. 102, 1389-1399. 
Blagosklonny, M.V., 2007d. Research by retrieving experiments. Cell Cycle. 6, 1277-1283.

Blagosklonny, M.V., 2008a. Aging, stem cells, and mammalian target of rapamycin: a prospect of pharmacologic rejuvenation of aging stem cells. Rejuvenation Res. 11, 801-808.

Blagosklonny, M.V., 2008b. Aging: ROS or TOR. Cell Cycle. 7, 3344-3354.

Blagosklonny, M.V., 2009a. Aging-suppressants: cellular senescence (hyperactivation) and its pharmacologic deceleration. Cell Cycle. 8, 1883-1887.

Blagosklonny, M.V., 2009b. Validation of anti-aging drugs by treating age-related diseases. Aging. 1, 281-288.

Blagosklonny, M.V., 2010a. Metformin and sex: Why suppression of aging may be harmful to young male mice. Aging. 2, 897-899.

Blagosklonny, M.V., 2010b. Rapamycin and quasi-programmed aging: four years later. Cell Cycle. 9, 1859-1862.

Blagosklonny, M.V., 2010c. Why human lifespan is rapidly increasing: solving "longevity riddle" with "revealed-slow-aging" hypothesis. Aging. 2, 177-182.

Blagosklonny, M.V., 2010d. Why men age faster but reproduce longer than women: mTOR and evolutionary perspectives. Aging. 2, 265-273.

Blagosklonny, M.V., 2010e. Why the disposable soma theory cannot explain why women live longer and why we age. Aging. 2, 884-887.

Blagosklonny, M.V., 2011a. Cell cycle arrest is not senescence. Aging. 3, 94-101.

Blagosklonny, M.V., 2011b. NCI's provocative questions on cancer: some answers to ignite discussion. Oncotarget. 2, 1352-1367.

Blagosklonny, M.V., 2012a. Answering the ultimate question "what is the proximal cause of aging?". Aging. 4, 861-877.

Blagosklonny, M.V., 2012b. Cell cycle arrest is not yet senescence, which is not just cell cycle arrest: terminology for TOR-driven aging. Aging. 4, 159-165.

Blagosklonny, M.V., 2012c. Prospective treatment of age-related diseases by slowing down aging. Am J Pathol. 181, 1142-1146.

Blagosklonny, M.V., 2013a. Big mice die young but large animals live longer. Aging. 5, 227-233.

Blagosklonny, M.V., 2013b. M(o)TOR of aging: MTOR as a universal molecular hypothalamus. Aging. 5, 490-494.

Blagosklonny, M.V., 2013c. MTOR-driven quasi-programmed aging as a disposable soma theory: Blind watchmaker vs. intelligent designer. Cell Cycle. 12, 1842-1847.

Blagosklonny, M.V., 2013d. TOR-centric view on insulin resistance and diabetic complications: perspective for endocrinologists and gerontologists. Cell Death Dis. 4, e964.

Blagosklonny, M.V., 2014a. Geroconversion: irreversible step to cellular senescence. Cell Cycle. 13, 3628-3635.

Blagosklonny, M.V., 2014b. Koschei the immortal and anti-aging drugs. Cell Death Dis. 5, e1552.

Blagosklonny, M.V., 2018a. Does rapamycin slow down time? Oncotarget. 9, 30210-30212.

Blagosklonny, M.V., 2018b. Rapamycin, proliferation and geroconversion to senescence. Cell Cycle. $17,2655-2665$.

Blagosklonny, M.V., 2019a. Rapamycin for longevity: opinion article. Aging. 11, 8048-8067.

Blagosklonny, M.V., 2019b. Rapamycin for the aging skin. Aging. 11, 12822-12826.

Blagosklonny, M.V., 2021. DNA- and telomere-damage does not limit lifespan: evidence from rapamycin. Aging. 13, 3167-3175.

Blagosklonny, M.V. and Darzynkiewicz, Z., 2002. Four birds with one stone: RAPA as potential anticancer therapy. Cancer Biol. Ther. 1, 359-361.

Blagosklonny, M.V. and Hall, M.N., 2009. Growth and aging: a common molecular mechanism. Aging. 1, 357-362.

Blagosklonny, M.V. and Pardee, A.B., 2002. Conceptual biology: unearthing the gems. Nature. 416, 373.

Calabrese, E., Baldwin, L. and Holland, C., 1999. Hormesis: a highly generalizable and reproducible phenomenon with important implications for risk assessment. Risk Anal. 19, 261-281.

Chandrashekar, V., Zaczek, D. and Bartke, A., 2004. The consequences of altered somatotropic system on reproduction. Biol. Reprod. 71, 17-27.

Charnov, E.L., 1993. Life History Invariants. Some Explorations of Symmetry in Evolutionary Ecology, Oxford University Press, Oxford. 
Chong, E.W., Wong, T.Y., Kreis, A.J., Simpson, J.A. and Guymer, R.H., 2007. Dietary antioxidants and primary prevention of age related macular degeneration: systematic review and metaanalysis. BMJ. 335, 755.

Clancy, D., Gems, D., Harshman, L.G., Oldham, S., Hafen, E., Leevers, S.J. and Partridge, L., 2001. Extension of lifespan by loss of chico, a Drosophila insulin receptor substrate protein. Science. 292, 104-106.

Cole, J.J., Robertson, N.A., Rather, M.I., Thomson, J.P., McBryan, T., Sproul, D., Wang, T., Brock, C., Clark, W., Ideker, T., Meehan, R.R., Miller, R.A., Brown-Borg, H.M. and Adams, P.D., 2017. Diverse interventions that extend mouse lifespan suppress shared age-associated epigenetic changes at critical gene regulatory regions. Genome Biol. 18, 58.

Comfort, A., 1979. The Biology of Senescence, Third edition ed. Elsevier, New York.

Consortium, M.M., 2021. Universal DNA methylation age across mammalian tissues. bioRxiv doi: https://doi.org/10.1101/2021.01.18.426733

Cutler, R.G., 1984. Evolutionary biology of aging and longevity in mammalian species, in: Johnson, J.E. (Ed.), Aging and Cell Function. Springer, Boston, pp. 1-147.

de Grey, A.D., Ames, B.N., Andersen, J.K., Bartke, A., Campisi, J., Heward, C.B., McCarter, R.J. and Stock, G., 2002. Time to talk SENS: critiquing the immutability of human aging. Ann. N Y Acad. Sci. . 959, 452-462.

de la Guardia, Y., Gilliat, A.F., Hellberg, J., Rennert, P., Cabreiro, F. and Gems, D., 2016. Run-on of germline apoptosis promotes gonad senescence in C. elegans. Oncotarget. 7, 39082-39096.

De Magalhaes, J. and Sandberg, A., 2005. Cognitive aging as an extension of brain development: a model linking learning, brain plasticity, and neurodegeneration. Mech. Ageing Dev. 126, 10261033.

de Magalhães, J.P., 2012. Programmatic features of aging originating in development: aging mechanisms beyond molecular damage? FASEB J. 26, 4821-4826.

de Magalhães, J.P., 2005. Open-minded scepticism: inferring the causal mechanisms of human ageing from genetic perturbations. Ageing Res. Rev. 4, 1-22.

de Magalhães, J.P. and Church, G.M., 2005. Genomes optimize reproduction: aging as a consequence of the developmental program. Physiology. 20, 252-259.

Demaria, M., Ohtani, N., Youssef, S., Rodier, F., Toussaint, W., Mitchell, J., Laberge, R., Vijg, J., Van Steeg, H., Dollé, M., Hoeijmakers, J., de Bruin, A., Hara, E. and Campisi, J., 2014. An essential role for senescent cells in optimal wound healing through secretion of PDGF-AA. Dev. Cell. 31, 722-733.

Demidenko, Z., Zubova, S., Bukreeva, E., Pospelov, V., Pospelova, T. and Blagosklonny, M., 2009 a. Rapamycin decelerates cellular senescence. Cell Cycle. 8, 1888-1895.

Demidenko, Z.N. and Blagosklonny, M.V., 2008. Growth stimulation leads to cellular senescence when the cell cycle is blocked. Cell Cycle. 7, 3355-3361.

Demidenko, Z.N. and Blagosklonny, M.V., 2009. At concentrations that inhibit mTOR, resveratrol suppresses cellular senescence. Cell Cycle. 8, 1901-1904.

Demidenko, Z.N., Korotchkina, L.G., Gudkov, A.V. and Blagosklonny, M.V., 2010. Paradoxical suppression of cellular senescence by p53. Proc. Natl. Acad. Sci. U S A. 107, 9660-9664.

Demidenko, Z.N., Shtutman, M. and Blagosklonny, M.V., 2009b. Pharmacologic inhibition of MEK and PI-3K converges on the mTOR/S6 pathway to decelerate cellular senescence. Cell Cycle. 8, 1896-1900.

Dilman, V.M., 1971. Age-associated elevation of hypothalamic threshold to feedback control, and its role in development, ageing, and disease. Lancet. 297, 1211-1219.

Dilman, V.M., 1984. Three models of medicine. Medical Hypotheses. 15, 185-208.

Dilman, V.M., 1986. Ontogenetic model of ageing and disease formation and mechanisms of natural selection. J. Theor. Biol. 118, 73-81.

Dilman, V.M., 1994. Development, Aging and Disease: A New Rationale for an Intervention Strategy, Harwood Academic Publishers.

Dufour, E., Boulay, J., Rincheval, V. and Sainsard-Chanet, A., 2000. A causal link between respiration and senescence in Podospora anserina. Proc. Natl. Acad. Sci. U S A. 97, 4138-4143.

Ezcurra, M., Benedetto, A., Sornda, T., Gilliat, A.F., Au, C., Zhang, Q., van Schelt, S., Petrache, A.L., Wang, H., de la Guardia, Y., Bar-Nun, S., Tyler, E., Wakelam, M.J. and Gems, D., 2018. C. 
elegans eats its own intestine to make yolk leading to multiple senescent pathologies. Curr. Biol. 28, 2544-2556.

Finch, C.E., 1990. Longevity, Senescence and the Genome, University of Chicago Press, Chicago and London.

Fontana, L., Partridge, L. and Longo, V.D., 2010. Extending healthy life span--from yeast to humans. Science. 328, 321-326.

Gaillard, J.-M. and Lemaître, J.-F., 2017. The Williams' legacy: A critical reappraisal of his nine predictions about the evolution of senescence. Evolution. 71, 2768-2785.

Galimov, E.R. and Gems, D., 2021. Death happy: Adaptive death and its evolution by kin selection in organisms with colonial ecology. Philos. Trans. R. Soc. B. 376, 20190730.

Galimov, E.R., Lohr, J.N. and Gems, D., 2019. When and how can death be an adaptation? Biochemistry (Moscow). 84, 1433-1437.

Gems, D., 2015. The aging-disease false dichotomy: understanding senescence as pathology. Front. Genet. 6, 212.

Gems, D. and de Magalhães, J.P., 2021. The hoverfly and the wasp: A critique of the hallmarks of aging as a paradigm. Ageing Res. Rev. 70, 101407.

Gems, D. and Doonan, R., 2009. Antioxidant defense and aging in C. elegans: is the oxidative damage theory of aging wrong? Cell Cycle. 8, 1681-7.

Gems, D., Kern, C.C., Nour, J. and Ezcurra, M., 2021. Reproductive suicide: similar mechanisms of aging in C. elegans and Pacific salmon. Frontiers Cell Dev. Biol. 9, 688788.

Gems, D. and McElwee, J.J., 2005. Broad spectrum detoxification: the major longevity assurance process regulated by insulin/IGF-1 signaling? Mech. Ageing Dev. 126, 381-387.

Gems, D. and Partridge, L., 2001. Insulin/IGF signalling and ageing: seeing the bigger picture. Curr. Op. Genet. Dev. 11, 287-292.

Gems, D. and Partridge, L., 2008. Stress-response hormesis and aging: "that which does not kill us makes us stronger". Cell Metab. 7, 200-3.

Gould, S.J., 1997. The exaptive excellence of spandrels as a term and prototype. Proc. Natl. Acad. Sci. U S A. 94, 10750-10755.

Gould, S.J. and Lewontin, R.C., 1979. The spandrels of San Marco and the Panglossian paradigm: a critique of the adaptationist programme. Proc. R. Soc. Lond. B. 205, 581-598.

Gould, S.J. and Vrba, E.S., 1982. Exaptation - a missing term in the science of form. Paleobiology. 8, 4-15.

Grandison, R.C., Piper, M.D. and Partridge, L., 2009. Amino-acid imbalance explains extension of lifespan by dietary restriction in Drosophila. Nature. 462, 1061-1064.

Haldane, J.B.S., 1941. New Paths in Genetics, Allen and Unwin, London.

Hamilton, W.D., 1966. The moulding of senescence by natural selection. J. Theor. Biol. 12, 12-45.

Hansen, M., Taubert, S., Crawford, D., Libina, L., Lee, S.-J. and Kenyon, C., 2007. Lifespan extension by conditions that inhibit translation in Caenorhabditis elegans. Aging Cell. 6, 95-110.

Harman, D., 1956. Aging: A theory based on free radical and radiation chemistry. J. Gerontol. 11, 298-300.

Harvey, P.H. and Purvis, A., 1999. Understanding the ecological and evolutionary reasons for life history variation: mammals as a case study, in: McGlade, J. (Ed.), Advanced Ecological Theory: Principles and Applications. Blackwell Science, Oxford, pp. 232-248.

Hayflick, L., 2007. Entropy explains aging, genetic determinism explains longevity, and undefined terminology explains misunderstanding both. PLoS Genet. 3, e220.

Hipkiss, A.R., 2007. On why decreasing protein synthesis can increase lifespan. Mech. Ageing Dev. $128,412-414$.

Holliday, R., 1989. Food, reproduction and longevity: is the extended lifespan of calorie-restricted animals an evolutionary adaptation? BioEssays. 10, 125-127.

Holzenberger, M., Dupont, J., Ducos, B., Leneuve, P., Geloen, A., Even, P., Cervera, P. and Le Bouc, Y., 2003. IGF-1 receptor regulates lifespan and resistance to oxidative stress in mice. Nature. $421,182-187$.

Honda, Y. and Honda, S., 1999. The daf-2 gene network for longevity regulates oxidative stress resistance and Mn-superoxide dismutase gene expression in Caenorhabditis elegans. FASEB J. 13, 1385-1393.

Horvath, S., 2013. DNA methylation age of human tissues and cell types. Genome Biol. 14, R115. 
Horvath, S., Lu, A.T., Cohen, H. and Raj, K., 2019. Rapamycin retards epigenetic ageing of keratinocytes independently of its effects on replicative senescence, proliferation and differentiation. Aging. 11, 3238-3249.

Horvath, S. and Raj, K., 2018. DNA methylation-based biomarkers and the epigenetic clock theory of ageing. Nat. Rev. Genet. 19, 371-384.

Howes, R.M., 2006. The free radical fantasy: a panoply of paradoxes. Ann. N Y Acad. Sci. 1067, 2226.

Işıldak, U., Somel, M., Thornton, J.M. and Dönertaş, H.M., 2020. Temporal changes in the gene expression heterogeneity during brain development and aging. Sci. Rep. 10, 4080.

Keaney, M. and Gems, D., 2003. No increase in lifespan in Caenorhabditis elegans upon treatment with the superoxide dismutase mimetic EUK-8. Free Radical Biol. Med. 34, 277-282.

Keaney, M., Matthijssens, F., Sharpe, M., Vanfleteren, J.R. and Gems, D., 2004. Superoxide dismutase mimetics elevate superoxide dismutase activity in vivo but do not retard aging in the nematode Caenorhabditis elegans. Free Radical Biol. Med. 37, 239-250.

Kenyon, C., 2010. The genetics of ageing. Nature. 464, 504-512.

Kirkwood, T., 2010. Why women live longer. Stress alone does not explain the longevity gap. Sci. Am. 303, 34-35.

Kirkwood, T.B., 2005. Understanding the odd science of aging. Cell. 120, 437-447.

Kirkwood, T.B. and Shanley, D.P., 2005. Food restriction, evolution and ageing. Mech. Ageing Dev. 126, 1011-1016.

Kirkwood, T.B.L., 1977. Evolution of ageing. Nature. 270, 301-304.

Kirkwood, T.B.L. and Rose, M.R., 1991. Evolution of senescence: late survival sacrificed for reproduction. Phil. Trans. R. Soc. London. 332, 15-24.

Klass, M.R., 1977. Aging in the nematode Caenorhabditis elegans: major biological and environmental factors influencing life span. Mech. Ageing Develop. 6, 413-429.

Labbadia, J. and Morimoto, R.I., 2014. Proteostasis and longevity: when does aging really begin? F1000Prime Rep. 6, 7.

Leontieva, O.V. and Blagosklonny, M.V., 2016. Gerosuppression by pan-mTOR inhibitors. Aging. 8, 3535-3551

Leontieva, O.V., Demidenko, Z.N. and Blagosklonny, M.V., 2015. Dual mTORC1/C2 inhibitors suppress cellular geroconversion (a senescence program). Oncotarget. 6, 23238-23248.

Leontieva, O.V., Natarajan, V., Demidenko, Z.N., Burdelya, L.G., Gudkov, A.V. and Blagosklonny, M.V., 2012a. Hypoxia suppresses conversion from proliferative arrest to cellular senescence. Proc. Natl. Acad. Sci. U S A. 109, 13314-1338.

Leontieva, O.V., Paszkiewicz, G.M. and Blagosklonny, M.V., 2012b. Mechanistic or mammalian target of rapamycin (mTOR) may determine robustness in young male mice at the cost of accelerated aging. Aging. 4, 899-916.

Lithgow, G. and Walker, G., 2002. Stress resistance as a determinate of C. elegans lifespan. Mech. Ageing Dev. 123, 765-771.

Lithgow, G.J., White, T.M., Melov, S. and Johnson, T.E., 1995. Thermotolerance and extended lifespan conferred by single-gene mutations and induced by thermal stress. Proc. Natl. Acad. Sci. USA. 92, 7540-7544.

Loeb, J. and Northrop, J.H., 1917. On the influence of food and temperature upon the duration of life. J. Biol. Chem. 32, 103-121.

Lohr, J., Galimov, E.R. and Gems, D., 2019. Does senescence promote fitness in Caenorhabditis elegans by causing death? Ageing Res. Rev. 50, 58-71.

Ludwig, F.C., 1980. What to expect from gerontological research? Science. 209, 1071.

Lui, J.C., Chen, W., Barnes, K.M. and Baron, J., 2010. Changes in gene expression associated with aging commonly originate during juvenile growth. Mech. Ageing Dev. 131, 641-649.

Macdonald, A.A., 2018. Aberrant growth of maxillary canine teeth in male babirusa (genus Babyrousa) Comptes Rendus Biologies. 341, 245-255.

Maklakov, A.A. and Chapman, T., 2019. Evolution of ageing as a tangle of trade-offs: energy versus function. Proc. Biol. Sci. 286, 20191604.

Masoro, E. and Austad, S., 1996. The evolution of the antiaging action of dietary restriction: a hypothesis. J. Gerontol. A Biol. Sci. Med. Sci. 51, B387-B391. 
Matsuyama, M., WuWong, D.J., Horvath, S. and Matsuyama, S., 2019. Epigenetic clock analysis of human fibroblasts in vitro: effects of hypoxia, donor age, and expression of hTERT and SV40 largeT. Aging. 11, 3012-30122.

McCay, C.M. and Crowell, M.F., 1934. Prolonging the life span. Scientific Monthly. 39, 405-414.

Medawar, P.B., 1952. An Unsolved Problem Of Biology, H.K. Lewis, London.

Moorad, J., Promislow, D. and Silvertown, J., 2019. Evolutionary ecology of senescence and a reassessment of Williams' 'extrinsic mortality' hypothesis. Trends Ecol. Evol. 34, 519-530.

Munoz-Espin, D. and Serrano, M., 2014. Cellular senescence: from physiology to pathology. Nat. Rev. Mol. Cell. Biol. 15, 482-496.

Nacusi, L.P. and Tindall, D.J., 2011. Targeting 5alpha-reductase for prostate cancer prevention and treatment. Nat. Rev. Urol. 8, 378-384.

Napalkov, N.P., 2001. The scientific career of V. M. Dil'man. Vopr. Onkol. 47, 135-138.

Nesse, R.M. and Williams, G.C., 1994. Why We Get Sick: The New Science of Darwinian Medicine, Random House.

Northrop, J.H., 1917. The effect of prolongation of the period of growth on the total duration of life. J. Biol. Chem. 32, 123-126.

Olovnikov, A., 1996. Telomeres, telomerase, and aging: origin of the theory. Exp. Gerontol. 31, 443448.

Osborne, T.B., Mendel, L.B. and Ferry, E.L., 1917. The effect of retardation of growth upon the breeding period and duration of life of rats. Science. 45, 294-295.

Park, H.W., 2010. Longevity, aging, and caloric restriction: Clive Maine McCay and the construction of a multidisciplinary research program. Historical Studies in the Natural Sciences. 40, 79-124.

Partridge, L. and Gems, D., 2002a. The evolution of longevity. Curr. Biol. 12, R544-R546.

Partridge, L. and Gems, D., 2002b. A lethal side-effect. Nature. 418, 921.

Partridge, L. and Gems, D., 2006. Beyond the evolutionary theory of ageing, from functional genomics to evo-gero. Trends Ecol. Evol. 21, 334-340.

Pearl, R., 1928. The Rate of Living, Knopf, New York.

Perez, V.I., Bokov, A., Van Remmen, H., Mele, J., Ran, Q., Ikeno, Y. and Richardson, A., 2009. Is the oxidative stress theory of aging dead? Biochim. Biophys. Acta. 1790, 1005-1014.

Petkovich, D.A., Podolskiy, D.I., Lobanov, A.V., Lee, S.G., Miller, R.A. and Gladyshev, V.N., 2017. Using DNA methylation profiling to evaluate biological age and longevity interventions. Cell Metab. 25, 954-960.e6.

Piper, M., Soultoukis, G., Blanc, E., Mesaros, A., Herbert, S., Juricic, P., He, X., Atanassov, I., Salmonowicz, H., Yang, M., Simpson, S., Ribeiro, C. and Partridge, L., 2017. Matching dietary amino acid balance to the in silico-translated exome optimizes growth and reproduction without cost to lifespan. Cell Metab. 25, 610-621.

Poulsen, P., Kyvik, K.O., Vaag, A. and Beck-Nielsen, H., 1999. Heritability of type II (non-insulindependent) diabetes mellitus and abnormal glucose tolerance-a population-based twin study. Diabetologia. 42, 139-145.

Promislow, D.E., 1993. On size and survival: progress and pitfalls in the allometry of life span. J. Gerontol. 48, B115-123.

Radak, Z., Chung, H.Y. and Goto, S., 2005. Exercise and hormesis: oxidative stress-related adaptation for successful aging. Biogerontology. 671-675.

Raj, K. and Horvath, S., 2020. Current perspectives on the cellular and molecular features of epigenetic ageing. Exp. Biol. Med. 245, 1532-1542.

Rea, S.L., Wu, D., Cypser, J.R., Vaupel, J.W. and Johnson, T.E., 2005. A stress-sensitive reporter predicts longevity in isogenic populations of Caenorhabditis elegans. Nat. Genet. 37, 894-898.

Ristow, M. and Zarse, K., 2010. How increased oxidative stress promotes longevity and metabolic health: The concept of mitochondrial hormesis (mitohormesis). Exp. Gerontol. 45, 410-408.

Schulz, T.J., Zarse, K., Voigt, A., Urban, N., Birringer, M. and Ristow, M., 2007. Glucose restriction extends Caenorhabditis elegans life span by inducing mitochondrial respiration and increasing oxidative stress. Cell Metab. 6, 280-293.

Schumacher, B., Pothof, J., Vijg, J. and Hoeijmakers, J.H.J., 2021. The central role of DNA damage in the ageing process. Nature. 592, 695-703. 
Shields, H.J., Traa, A. and Van Raamsdonk, J.M., 2021. Beneficial and detrimental effects of reactive oxygen species on lifespan: a comprehensive review of comparative and experimental studies. Front. Cell Dev. Biol. 9, 628157.

Shore, D.E. and Ruvkun, G., 2013. A cytoprotective perspective on longevity regulation. Trends Cell Biol. 23 409-420.

Sohal, R.S. and Weindruch, R., 1996. Oxidative stress, caloric restriction, and aging. Science. 273, 5963.

Somel, M., Guo, S., Fu, N., Yan, Z., Hu, H.Y., Xu, Y., Yuan, Y., Ning, Z., Hu, Y., Menzel, C., Hu, H., Lachmann, M., Zeng, R., Chen, W. and Khaitovich, P., 2010. MicroRNA, mRNA, and protein expression link development and aging in human and macaque brain. Genome Res. 20, 12071218.

Strehler, B.L., 1977. Time, cells, and aging, 2nd edn. Academic Press, New York.

Strenk, S.A., Strenk, L.M. and Koretz, J.F., 2005. The mechanism of presbyopia. Prog. Retin. Eye Res. 24, 379-393.

Takasugi, M., 2011. Progressive age-dependent DNA methylation changes start before adulthood in mouse tissues. Mech. Ageing Dev. 132, 65-71.

Tsang, C.K., Qi, H., Liu, L.F. and Zheng, X.F., 2007. Targeting mammalian target of rapamycin (mTOR) for health and diseases. Drug Discov. Today. 12, 112-124.

Tu, M.-P., Epstein, D. and Tatar, M., 2002. The demography of slow aging in male and female Drosophila mutant for the insulin-receptor substrate homolog chico. Aging Cell. 1, 75-80.

Untergasser, G., Madersbacher, S. and Berger, P., 2005. Benign prostatic hyperplasia: age-related tissue-remodeling. Exp. Gerontol. 40, 121-128.

Van Raamsdonk, J.M. and Hekimi, S., 2010. Reactive oxygen species and aging in Caenorhabditis elegans: causal or casual relationship? Antioxid. Redox Signal. 13, 1911-1953.

Vanfleteren, J.R., 1993. Oxidative stress and ageing in Caenorhabditis elegans. Biochem. J. 292, 605608.

Wang, H., Zhang, Z. and Gems, D., 2018a. Monsters in the uterus: teratoma-like tumors in senescent C. elegans result from a parthenogenetic quasi-program Aging 10, 1188-1189.

Wang, H., Zhao, Y., Ezcurra, M., Benedetto, A., Gilliat, A., Hellberg, J., Ren, Z., Athigapanich, T., Girstmair, J., Telford, M.J., Dolphin, C.T., Zhang, Z. and Gems, D., 2018b. A parthenogenetic quasi-program causes teratoma-like tumors during aging in wild-type C. elegans. NPJ Aging Mech. Disease. 4, 6.

Wang, T., Tsui, B., Kreisberg, J.F., Robertson, N.A., Gross, A.M., Yu, M.K., Carter, H., Brown-Borg, H.M., Adams, P.D. and Ideker, T., 2017. Epigenetic aging signatures in mice livers are slowed by dwarfism, calorie restriction and rapamycin treatment. Genome Biol. 18, 57.

Warner, H.R., 2004. The future of aging interventions. J. Gerontol. A Biol. Sci. Med. Sci. 59, B692B696.

Waters, D.J., Shen, S. and Glickman, L.T., 2000. Life expectancy, antagonistic pleiotropy, and the testis of dogs and men. The Prostate. 43, 272-277.

Weindruch, R. and Walford, R., 1982. Dietary restriction in mice beginning at 1 year of age: Effect on life span and spontaneous cancer incidence. Science. 215, 1415-1418.

Williams, G.C., 1957. Pleiotropy, natural selection and the evolution of senescence. Evolution. 11, 398-411.

Williams, G.C., 1996. Plan and Purpose in Nature, Weidenfeld and Nicholson.

Yang, W. and Hekimi, S., 2010. A mitochondrial superoxide signal triggers increased longevity in Caenorhabditis elegans. PLoS Biol. 8, e1000556.

Zajitschek, F., Georgolopoulos, G., Vourlou, A., Ericsson, M., Zajitschek, S., Friberg, U. and Maklakov, A., 2019. Evolution under dietary restriction decouples survival from fecundity in Drosophila melanogaster females. J. Gerontol. A Biol. Sci. Med. Sci. 74, 1542-1548.

Zhao, X. and Promislow, D.E.L., 2019. Senescence and ageing, in: Brüne, M. and Schiefenhövel, W. Eds.), The Oxford Handbook of Evolutionary Medicine. Oxford University Press, Oxford, UK, pp. 167-208.

Zhao, Y., Gilliat, A.F., Ziehm, M., Turmaine, M., Wang, H., Ezcurra, M., Yang, C., Phillips, G., McBay, D., Zhang, W.B., Partridge, L., Pincus, Z. and Gems, D., 2017. Two forms of death in aging Caenorhabditis elegans. Nat. Commun. 8, 15458.

Zimniak, P., 2008. Detoxification reactions: relevance to aging. Ageing Res. Rev. 7, 281-300. 


\section{Glossary}

Adaptive cellular senescence: A type of programmed cellular senescence, e.g. where "senescent" fibroblasts contribute to wound healing (Demaria et al., 2014). This contrasts with quasi-programmed, non-adaptive cellular senescence. In some cases cellular senescence may have both adaptive and futile elements, as when a cell leaves the cell cycle due to DNA damage (programmed, adaptive) and then becomes hypertrophic and hypersecretory (quasi-programmed, non-adaptive).

Antagonistic pleiotropy $(A P)$ : Where action of a given gene is both beneficial and detrimental to fitness. If the latter occurs later in life and is therefore subject to weaker selection, such a gene may be favored by natural selection, and promote aging (Williams, 1957).

Damage/maintenance paradigm: Theory that aging is largely caused by accumulation of molecular damage, which can be prevented by somatic maintenance functions. Various theories of aging are based on this broad assumption.

Disposable soma: Theory proposing that natural selection favors investment of limited resources into reproduction rather than somatic maintenance, accelerating damage accumulation and, therefore, senescence (Kirkwood, 1977).

Hyperfunction: Where wild-type gene action and biological function actively leads to senescent pathology, as opposed to passive random damage or wear and tear (Blagosklonny, 2006a).

Onion model (new term): This views aging as a nested series of life-limiting pathologies (Blagosklonny, 2006a; de Magalhães, 2012). Thus, lifespan is a function not of the overall aging process, but of those processes generating life-limiting pathologies. Which pathologies are life-limiting depends upon environment and animal species.

Programmed aging: Senescence caused by a relatively ordered series of biological processes that promotes fitness via inclusive fitness or group fitness. Evolutionary theory predicts that this does not occur in most animal species, but can in some cases (Galimov and Gems, 2021; Lohr et al., 2019).

Programmatic aging: Where senescence is genetically determined, including where complex biological processes contribute to senescence, but not necessarily to fitness (cf. quasi-programs, costly programs).

Quasi-programmed aging: Senescence caused by a relatively ordered series of biological processes that does not promote fitness; may occur due to futile run-on of wild-type programs that promote fitness earlier in life (Blagosklonny, 2006a).

Run-on: Futile continuation of gene function or processes in later life, leading to pathology (de la Guardia et al., 2016) (cf. quasi-program).

Selection shadow: Decrease in selection with increasing age, leading to weaker selection against genes with deleterious effects on fitness and health the later in life those effects are expressed. Environmental 
factors that increase mortality rate (e.g. predators, infectious pathogens, starvation) can deepen the selection shadow.

Senescence: The overall process of deterioration with age or the resulting pathological condition (not to be confused with cellular senescence (sensu Hayflick), which is a particular form of cell cycle arrest affecting some vertebrate cell types). Although aging has several meanings, in the biological context it is usually synonymous with senescence.

Ultimate-proximate theories of aging: These combine explanations of the evolutionary (ultimate) and mechanistic (proximate) causes of aging into a single integrated account. 
Table 1: Overview of articles by Misha Blagosklonny on theories of aging

\begin{tabular}{|c|c|c|}
\hline Source & Impact & Overview \\
\hline $\begin{array}{l}\text { Conceptual biology: unearthing the gems. } \\
\text { Blagosklonny MV, Pardee AB. Nature } 2002416 \\
\text { 373. }\end{array}$ & ** & $\begin{array}{l}\text { Describes conceptual research approach used later to } \\
\text { develop aging theories. }\end{array}$ \\
\hline $\begin{array}{l}\text { Four birds with one stone: RAPA as potential } \\
\text { anticancer therapy. Blagosklonny MV, } \\
\text { Darzynkiewicz Z. Cancer Biol. Ther. } 20021359- \\
361 .\end{array}$ & & $\begin{array}{l}\text { Initial interest in rapamycin. In normal cells } \\
\text { rapamycin blocks angiogenesis and protects against } \\
\text { chemotherapeutics; in cancer cells it reduces hypoxia } \\
\text { resistance and preferentially inhibits growth where } \\
\text { there is an overactive AKT/mTOR pathway. }\end{array}$ \\
\hline $\begin{array}{l}\text { Cell senescence and hypermitogenic arrest. } \\
\text { Blagosklonny MV. EMBO Rep. } 20034 \text { 358-362. }\end{array}$ & ** & $\begin{array}{l}\text { Proposes that cellular senescence results from exit } \\
\text { from the cell cycle combined with hypermitogenic } \\
\text { signals (but mTOR not yet mentioned) }\end{array}$ \\
\hline $\begin{array}{l}\text { Conceptual research and phenomenology- } \\
\text { harmonizing slices. Blagosklonny MV. Cell } \\
\text { Cycle } 20032 \text { 3-4. }\end{array}$ & & Recapitulates Nature 2002416373. \\
\hline $\begin{array}{l}\text { Aging and immortality: quasi-programmed } \\
\text { senescence and its pharmacologic inhibition. } \\
\text { Blagosklonny MV. Cell Cycle } 20065 \text { 2087-2102. }\end{array}$ & $* * *$ & $\begin{array}{l}\text { Introduces quasi-program (QP) and hyperfunction } \\
\text { (HF) concepts. mTOR HF promotes many diseases of } \\
\text { aging. mTOR has AP effects, promoting programs } \\
\text { then QPs. This limits lifespan but is only one cause of } \\
\text { aging. QPs are a major disease etiology and target of } \\
\text { intervention. Rapamycin could prevent senescent } \\
\text { multimorbidity. }\end{array}$ \\
\hline $\begin{array}{l}\text { Cell senescence: hypertrophic arrest beyond } \\
\text { the restriction point. Blagosklonny MV. J. Cell. } \\
\text { Physiol. } 2006209592-597 .\end{array}$ & & $\begin{array}{l}\text { Elaborates cell senescence as hypermitogenic arrest } \\
\text { hypothesis, and links to role of mTOR in aging. }\end{array}$ \\
\hline $\begin{array}{l}\text { An anti-aging drug today: from senescence- } \\
\text { promoting genes to anti-aging pill. } \\
\text { Blagosklonny MV. Drug Discov. Today. } 200712 \\
\text { 218-224. }\end{array}$ & & $\begin{array}{l}\text { Recapitulates mTOR-centric model of aging, } \\
\text { emphasizing therapeutic potential of rapamycin as } \\
\text { anti-aging drug. }\end{array}$ \\
\hline $\begin{array}{l}\text { Research by retrieving } \text { experiments. } \\
\text { Blagosklonny MV. Cell Cycle } 20076 \text { 1277-1283. }\end{array}$ & * & $\begin{array}{l}\text { A more detailed description of the conceptual research } \\
\text { approach, with examples. See Nature } 2002416373 \text {. }\end{array}$ \\
\hline $\begin{array}{l}\text { Program-like aging and mitochondria: instead } \\
\text { of random damage by free radicals. } \\
\text { Blagosklonny MV. J. Cell. Biochem. } 2007102 \\
\text { 1389-1399. }\end{array}$ & * & $\begin{array}{l}\text { Enlarged, respiration-defective mitochondria can } \\
\text { accumulate in aging cells. mTOR inhibits mitophagy } \\
\text { that would otherwise eliminate them. }\end{array}$ \\
\hline $\begin{array}{l}\text { Paradoxes of aging. Blagosklonny MV. Cell } \\
\text { Cycle } 200762997-3003 .\end{array}$ & $* * *$ & $\begin{array}{l}\text { QPs promoted by mTOR/IIS provide a better } \\
\text { explanation than DS for life extension by dietary } \\
\text { restriction, inhibition of protein synthesis, hormesis } \\
\text { and other phenomena. Lifespan is a function of } \\
\text { diseases caused by QPs, not a direct consequence of } \\
\text { damage accumulation. }\end{array}$ \\
\hline $\begin{array}{l}\text { Cancer and aging: more puzzles, more } \\
\text { promises? Blagosklonny MV, Campisi J. Cell } \\
\text { Cycle 2008 } 7 \text { 2615-2618. }\end{array}$ & & $\begin{array}{l}\text { Discussion of finding from Anisimov lab that } \\
\text { metformin can increase lifespan in SHR mice without } \\
\text { affecting cancer incidence and onset. }\end{array}$ \\
\hline $\begin{array}{l}\text { Aging, stem cells, and mammalian target of } \\
\text { rapamycin: a prospect of pharmacologic } \\
\text { rejuvenation of aging stem cells. Blagosklonny } \\
\text { MV. Rejuvenation Res. } 200811801-808 \text {. }\end{array}$ & $* *$ & $\begin{array}{l}\text { Proposes the hypothesis that } \mathrm{mTOR} \text { hyperfunction in } \\
\text { stem cells leads to insensitivity to activating stimuli, } \\
\text { causing age decline; hence rapamycin should restore } \\
\text { stem cell function. More broadly, mTOR promotes } \\
\text { signal insensitivity as a brake to growth, and this } \\
\text { promotes aging. }\end{array}$ \\
\hline
\end{tabular}




\begin{tabular}{|c|c|c|}
\hline $\begin{array}{l}\text { Prevention of cancer by inhibiting aging. } \\
\text { Blagosklonny MV. Cancer Biol. Ther. } 20087 \\
\text { 1520-1524. }\end{array}$ & $*$ & $\begin{array}{l}\text { Summarizes evidence that aging, particularly mTOR } \\
\text { activity, promotes cancer, and that mTOR inhibition } \\
\text { could prevent aging-related cancer. Aging promotes } \\
\text { progression from latent to clinical cancer. }\end{array}$ \\
\hline $\begin{array}{l}\text { Aging: ROS or TOR. Blagosklonny MV. Cell } \\
\text { Cycle } 200873344-3354 \text {. }\end{array}$ & $* * *$ & $\begin{array}{l}\text { Better evidence for role of mTOR hyperfunction than } \\
\text { ROS as a cause of diseases of aging. Critique of the } \\
\text { oxidative damage theory of aging. }\end{array}$ \\
\hline $\begin{array}{l}\text { Aging-suppressants: cellular senescence } \\
\text { (hyperactivation) and its pharmacologic } \\
\text { deceleration. Blagosklonny MV. Cell Cycle } 2009 \\
8 \text { 1883-1887. }\end{array}$ & & $\begin{array}{l}\text { Discussion of } 3 \text { papers from his own lab, in Cell Cycle } \\
2009 \text { 8. Pharmacological inhibition of TOR, PI-3K, } \\
\text { MEK after p16, p21-driven cell cycle arrest inhibits } \\
\text { irreversible cellular senescence. Growth pathways } \\
\text { drive arrested cells into cellular senescence. }\end{array}$ \\
\hline $\begin{array}{l}\text { TOR-driven aging: speeding car without } \\
\text { brakes. Blagosklonny MV. Cell Cycle } 20098 \\
\text { 4055-4059. }\end{array}$ & & $\begin{array}{l}\text { Recaps main theory using an analogy. Aging is not like } \\
\text { a rusting car, but one without brakes. TOR is the } \\
\text { engine, driving pathogenic quasi-programs, } \\
\text { rapamycin a brake. }\end{array}$ \\
\hline $\begin{array}{l}\text { Validation of anti-aging drugs by treating age- } \\
\text { related diseases. Blagosklonny MV. Aging } 2009 \\
1281-288 .\end{array}$ & $*$ & $\begin{array}{l}\text { A good biomarker of aging to detect anti-aging drug } \\
\text { effects is multiple diseases of aging. Anti-aging effects } \\
\text { can be detected by retrospective analysis of data from } \\
\text { drug trials against individual diseases (data } \\
\text { repurposing). }\end{array}$ \\
\hline $\begin{array}{l}\text { Growth and aging: a common molecular } \\
\text { mechanism. Blagosklonny MV, Hall MN. } \\
\text { Aging } 20091357-362 \text {. }\end{array}$ & & $\begin{array}{l}\text { Concise overview of the biology of mTOR and its role } \\
\text { in aging, including a greater emphasis on effects in } \\
\text { budding yeast. }\end{array}$ \\
\hline $\begin{array}{l}\text { Inhibition of S6K by resveratrol: in search of } \\
\text { the purpose. Blagosklonny MV. Aging } 20091 \\
511-514 .\end{array}$ & & $\begin{array}{l}\text { Response to report in Aging that resveratrol inhibits S6 } \\
\text { kinase. Resveratrol effects on aging may work through } \\
\text { mTOR pathway. Rapamycin action on aging is an } \\
\text { unintended effect of a growth inhibiting antifungal; a } \\
\text { similar, "side effect" type explanation for resveratrol } \\
\text { action on aging is more plausible than the } \\
\text { xenohormesis hypothesis. }\end{array}$ \\
\hline $\begin{array}{l}\text { Linking calorie restriction to longevity } \\
\text { through sirtuins and autophagy: any role for } \\
\text { TOR. } \\
\text { Blagosklonny MV. Cell Death Dis. } 20101 \mathrm{e} 12 \text {. }\end{array}$ & * & $\begin{array}{l}\text { Commentary on Morselli E et al. Cell Death Dis. } 20101 \\
\text { e10, which reports that CR and resveratrol increase } \\
\text { lifespan by increasing autophagy. Argues against } \\
\text { autophagy/lysosome decline as a primary cause of } \\
\text { aging. }\end{array}$ \\
\hline $\begin{array}{l}\text { Calorie restriction: decelerating mTOR-driven } \\
\text { aging from cells to organisms (including } \\
\text { humans). } \\
\text { Blagosklonny MV. Cell Cycle } 20109683-688 \text {. }\end{array}$ & & $\begin{array}{l}\text { Recapitulates arguments that DR acts by inhibiting } \\
\text { mTOR, and arguments against the molecular damage } \\
\text { and allocation hypotheses. }\end{array}$ \\
\hline $\begin{array}{l}\text { Why human lifespan is rapidly increasing: } \\
\text { solving "longevity riddle" with "revealed- } \\
\text { slow-aging" hypothesis. Blagosklonny MV. } \\
\text { Aging } 20102177-182 \text {. }\end{array}$ & $* *$ & $\begin{array}{l}\text { Proposes novel hypothesis for the human mortality } \\
\text { rate transition, Vaupel JW. Nature } 2010464 \text { 536: higher } \\
\text { past early mortality of individuals with higher TOR } \\
\text { levels. }\end{array}$ \\
\hline $\begin{array}{l}\text { Rapamycin and quasi-programmed aging: } \\
\text { four years later. Blagosklonny MV. Cell Cycle } \\
20109 \text { 1859-1862. }\end{array}$ & * & $\begin{array}{l}\text { Describes how } 12 \text { predictions of the key Cell Cycle } 2006 \\
52087 \text { have been borne out by subsequent work. }\end{array}$ \\
\hline $\begin{array}{l}\text { Why men age faster but reproduce longer than } \\
\text { women: mTOR and evolutionary perspectives. } \\
\text { Blagosklonny MV. Aging } 20102265-273 \text {. }\end{array}$ & $* *$ & $\begin{array}{l}\text { Argues that mTOR activity is higher in men, and } \\
\text { reiterates Dilman's theory that menopause is due to a } \\
\text { quasi-program: run-on of the decline in hypothalamic } \\
\text { sensitivity to inhibition by estrogen that triggers } \\
\text { puberty by allowing FSH production. Later }\end{array}$ \\
\hline
\end{tabular}




\begin{tabular}{|c|c|c|}
\hline & & $\begin{array}{l}\text { hypothalamic insensitivity leads to FSH over- } \\
\text { production, causing a futile acceleration of follicular } \\
\text { atresia. }\end{array}$ \\
\hline $\begin{array}{l}\text { Revisiting the antagonistic pleiotropy theory } \\
\text { of aging: TOR-driven program and quasi- } \\
\text { program. } \\
\text { Blagosklonny MV. Cell Cycle } 201093151-3156 .\end{array}$ & ** & $\begin{array}{l}\text { Critique of Kirkwood TB. Cell } 2005120437 \text { claim that } \\
\text { p53 exhibits AP. Argues instead that mTOR and IIS } \\
\text { pathway genes exhibit AP, and rapamycin is a } \\
\text { reversed-AP drug. }\end{array}$ \\
\hline $\begin{array}{l}\text { Increasing healthy lifespan by suppressing } \\
\text { aging in our lifetime: preliminary proposal. } \\
\text { Blagosklonny MV. Cell Cycle } 201094788-4794 \text {. }\end{array}$ & & $\begin{array}{l}\text { Introduces term post-aging syndrome for senescence } \\
\text { where mTOR hyperfunction is suppressed. }\end{array}$ \\
\hline $\begin{array}{l}\text { Why the disposable soma theory cannot } \\
\text { explain why women live longer and why we } \\
\text { age. Blagosklonny MV. Aging } 20102884-887 \text {. }\end{array}$ & $*$ & $\begin{array}{l}\text { Critique of Kirkwood T. "Why women live longer." } \\
\text { Sci Am } 2010 \quad 303 \quad 34 \text {, and disposable soma. } \\
\text { Recapitulates arguments from Aging } 20102265 .\end{array}$ \\
\hline $\begin{array}{l}\text { Metformin and sex: Why suppression of aging } \\
\text { may be harmful to young male mice. } \\
\text { Blagosklonny MV. Aging } 20102897-9 \text {. }\end{array}$ & & $\begin{array}{l}\text { Commentary on finding that metformin increases } \\
\text { mortality rate in young adult male mice. Elaboration } \\
\text { of "revealed slow aging" hypothesis (Aging } 20102 \\
177 \text { ). }\end{array}$ \\
\hline $\begin{array}{l}\text { Cell cycle arrest is not senescence. } \\
\text { Blagosklonny MV. Aging } 2011394-101 .\end{array}$ & ** & $\begin{array}{l}\text { Development and extension of the hypermitogenic } \\
\text { arrest idea, including physiological senescence: growth } \\
\text { promotion in quiescent, wild-type cells in vivo leads } \\
\text { to hyperfunctional state; view of cancer cells as pro- } \\
\text { senescent: pathogenic hyperfunction seen in senescent } \\
\text { cells also occurs in cancer cells, contributing to } \\
\text { hallmarks of cancer. }\end{array}$ \\
\hline $\begin{array}{l}\text { Progeria, rapamycin and normal aging: recent } \\
\text { breakthrough. Blagosklonny MV. Aging } 20113 \\
685-691 .\end{array}$ & & $\begin{array}{l}\text { Commentary on finding that rapamycin suppresses } \\
\text { pro-senescent phenotype in cells from Hutchinson } \\
\text { Gilford progeria patients ( } S c i \text {. Transl. Med. } 20113 \\
\text { 89ra58). mTOR promotes progeria, including life- } \\
\text { shortening effects of obesity. Rapamycin could be a } \\
\text { treatment for progeria and normal aging. }\end{array}$ \\
\hline $\begin{array}{l}\text { Hormesis does not make sense except in the } \\
\text { light of TOR-driven aging. Blagosklonny MV. } \\
\text { Aging } 201131051-1062 \text {. }\end{array}$ & ** & $\begin{array}{l}\text { This argues against the interpretation that hormetic } \\
\text { effects on aging reflect suppression of molecular } \\
\text { damage. Proposes two types of hormesis. Hormesis } A \\
\text { acts by inhibiting mTOR. Hormesis B induces aging } \\
\text { tolerance: resistance to catastrophic complications of } \\
\text { aging (e.g. ischemic conditioning). }\end{array}$ \\
\hline $\begin{array}{l}\text { Molecular damage in cancer: an argument for } \\
\text { mTOR-driven aging. Blagosklonny MV. Aging } \\
20113 \text { 1130-1141. }\end{array}$ & $* *$ & $\begin{array}{l}\text { Molecular damage (mutation) is important in cancer, } \\
\text { but this is different to the standard damage/wear-and- } \\
\text { tear view of aging. Suggests an almost developmental } \\
\text { view of cancer ontogeny: "numerous random } \\
\text { mutations are selected for non-random activation of } \\
\text { mTOR". }\end{array}$ \\
\hline $\begin{array}{l}\text { NCI's provocative questions on cancer: some } \\
\text { answers to ignite discussion. Blagosklonny } \\
\text { MV. Oncotarget } 201121352-1367 \text {. }\end{array}$ & $*$ & $\begin{array}{l}\text { Response to US National Cancer Institute's } 24 \\
\text { questions about cancer. Includes good account of links } \\
\text { between aging, obesity and cancer (particularly those } \\
\text { involving mTOR). }\end{array}$ \\
\hline $\begin{array}{l}\text { Cell cycle arrest is not yet senescence, which is } \\
\text { not just cell cycle arrest: terminology for TOR- } \\
\text { driven aging. Blagosklonny MV. Aging } 20124 \\
\text { 159-165. }\end{array}$ & ** & $\begin{array}{l}\text { Develops concept of hypermitogenic arrest, using new } \\
\text { terminology including gerogenic conversion/ } \\
\text { geroconversion, and gerogenic oncogenes/gerogenes, to } \\
\text { give a more conceptually integrated account of the } \\
\text { roles of PI3K/RAS/mTOR action in aging and cancer. }\end{array}$ \\
\hline
\end{tabular}




\begin{tabular}{|c|c|c|}
\hline $\begin{array}{l}\text { Once again on rapamycin-induced insulin } \\
\text { resistance and longevity: despite of or owing } \\
\text { to. Blagosklonny MV. Aging } 20124350-358 .\end{array}$ & & $\begin{array}{l}\text { Response to study of diabetes-like condition in mice } \\
\text { under chronic rapamycin treatment (Science } 2012335 \\
\text { 1638). Argues this this "starvation diabetes", a form of } \\
\text { benevolent diabetes, and not an arguments against } \\
\text { rapamycin safety. }\end{array}$ \\
\hline $\begin{array}{l}\text { Prospective treatment of age-related diseases } \\
\text { by slowing down aging. Blagosklonny MV. } \\
\text { Am. J. Pathol. } 2012181 \text { 1142-1146. }\end{array}$ & & $\begin{array}{l}\text { Reiteration of preventative approach to reduce age- } \\
\text { related disease using rapamycin. Describes how } \\
\text { multiple forms of hyperfunction contribute to } \\
\text { atherosclerosis. }\end{array}$ \\
\hline $\begin{array}{l}\text { How to save Medicare: the anti-aging remedy. } \\
\text { Blagosklonny MV. Aging } 20124 \text { 547-552. }\end{array}$ & & $\begin{array}{l}\text { Deceleration of aging would reduce healthcare costs, } \\
\text { and could be achieved by mTOR inhibitors (e.g. } \\
\text { rapamycin). }\end{array}$ \\
\hline $\begin{array}{l}\text { Rapalogs in cancer prevention: anti-aging or } \\
\text { anticancer? Blagosklonny MV. Cancer Biol. } \\
\text { Ther. } 2012131349-1354 .\end{array}$ & & $\begin{array}{l}\text { Short review of evidence that rapalogs can prevent } \\
\text { cancer, at least in part by slowing aging. }\end{array}$ \\
\hline $\begin{array}{l}\text { Answering the ultimate question "what is the } \\
\text { proximal cause of aging?" Blagosklonny MV. } \\
\text { Aging } 20124861-877 \text {. }\end{array}$ & $*$ & $\begin{array}{l}\text { Response to Zimniak P. "What is the proximal cause } \\
\text { of aging?" Front. Genet. } 20123189 \text {, a critique of the } \\
\text { hyperfunction theory. Reiterates the theory, with } \\
\text { emphasis on disease causation. }\end{array}$ \\
\hline $\begin{array}{l}\text { Common drugs and treatments for cancer and } \\
\text { age-related diseases: revitalizing answers to } \\
\text { NCI's provocative questions. Blagosklonny } \\
\text { MV. Oncotarget } 201231711-1724 \text {. }\end{array}$ & & $\begin{array}{l}\text { Follow-up to Oncotarget } 201121352 \text {. More on aging, } \\
\text { obesity and cancer. A number of existing drugs (e.g. } \\
\text { ACE inhibitors) may have cancer preventative effects } \\
\text { by inhibiting mTOR. }\end{array}$ \\
\hline $\begin{array}{l}\text { Hypoxia, MTOR and autophagy: converging } \\
\text { on senescence or quiescence. Blagosklonny } \\
\text { MV. Autophagy } 20139260-262 \text {. }\end{array}$ & & $\begin{array}{l}\text { Discussion of his own paper, PNAS } 201210913314 . \\
\text { Hypoxia promotes geroconversion by inhibiting } \\
\text { mTOR. Also discusses possible significance of mTOR- } \\
\text { autophagy spatial coupling compartment (TASCC) in } \\
\text { senescent cells. }\end{array}$ \\
\hline $\begin{array}{l}\text { Big mice die young but large animals live } \\
\text { longer. Blagosklonny MV. Aging } 20135 \text { 227- } \\
\text { 233. }\end{array}$ & $* *$ & $\begin{array}{l}\text { Presents hypothesis that selection for slower aging } \\
\text { results in slower development. Large body size } \\
\text { (within species) can result from growing faster } \\
\text { (leading to faster aging) or (between species) } \\
\text { developing longer (leading to slower aging). }\end{array}$ \\
\hline $\begin{array}{l}\text { MTOR-driven quasi-programmed aging as a } \\
\text { disposable soma theory: blind watchmaker vs. } \\
\text { intelligent designer. Blagosklonny MV. Cell } \\
\text { Cycle } 201312 \text { 1842-1847. }\end{array}$ & & $\begin{array}{l}\text { Recapitulates arguments for hyperfunction theory and } \\
\text { against disposable soma theory. Hyperfunction theory } \\
\text { is disposable soma theory } 2 \text {. Aging is quasi- } \\
\text { programmed by the blind watchmaker (c.f. Dawkins). }\end{array}$ \\
\hline $\begin{array}{l}\text { M(o)TOR of aging: MTOR as a universal } \\
\text { molecular hypothalamus. Blagosklonny MV. } \\
\text { Aging } 20135490-494 \text {. }\end{array}$ & $*$ & $\begin{array}{l}\text { Reaction to Nature } 2013497211 \text {, evidence that } \\
\text { inflammation in the hypothalamus promotes mouse } \\
\text { aging. Argues that mTOR acts as a molecular } \\
\text { hypothalamus in the cell, integrating signals } \\
\text { generated by insulin, mitogens, cytokines, oxygen, } \\
\text { and nutrients. }\end{array}$ \\
\hline $\begin{array}{l}\text { Rapamycin extends life- and health span } \\
\text { because it slows aging. Blagosklonny MV. } \\
\text { Aging } 20135592-598 \text {. }\end{array}$ & & $\begin{array}{l}\text { Cogent critique of J Clin Invest. } 20131233272 \text { study } \\
\text { arguing that rapamycin prevents disease but not } \\
\text { aging. Reiterates key points made previously. }\end{array}$ \\
\hline $\begin{array}{l}\text { Damage-induced aging and perpetual motion. } \\
\text { Blagosklonny MV. Cell Cycle } 201312 \text { 2709- } \\
2710 .\end{array}$ & & $\begin{array}{l}\text { US Patent Office now refuses to grant patents for } \\
\text { perpetual motion machines. Should a similar policy be } \\
\text { made for papers claiming to show that aging is caused } \\
\text { by molecular damage? Reiterates key points made } \\
\text { previously. }\end{array}$ \\
\hline
\end{tabular}




\begin{tabular}{|c|c|c|}
\hline $\begin{array}{l}\text { Aging is not programmed: genetic pseudo- } \\
\text { program is a shadow of developmental } \\
\text { growth. } \\
\text { Blagosklonny MV. Cell Cycle. } 201312 \text { 3736- } \\
3742 .\end{array}$ & & $\begin{array}{l}\text { Account of hyperfunction theory aiming to correct the } \\
\text { misconception that the description of aging as quasi- } \\
\text { programmed means that the hyperfunction theory is a } \\
\text { programmed aging theory. }\end{array}$ \\
\hline $\begin{array}{l}\text { TOR-centric view on insulin resistance and } \\
\text { diabetic complications: perspective for } \\
\text { endocrinologists and gerontologists. } \\
\text { Blagosklonny MV. Cell Death Dis. } 20134 \text { e964. }\end{array}$ & $* *$ & $\begin{array}{l}\text { Account of how pathophysiology of type } 2 \text { diabetes, } \\
\text { including retinopathy, nephropathy and neuropathy, } \\
\text { can be understood as resulting from mTOR } \\
\text { hyperfunction rather than hyperglycemia. }\end{array}$ \\
\hline $\begin{array}{l}\text { Selective anti-cancer agents as anti-aging } \\
\text { drugs. Blagosklonny MV. Cancer Biol. Ther. } \\
201314 \text { 1092-1097. }\end{array}$ & & $\begin{array}{l}\text { Surveys anticancer drugs that target proteins that also } \\
\text { promote aging. Using them geroprotectively will } \\
\text { protect against cancer. Some reiteration of Cancer Biol. } \\
\text { Ther. } 2012131349 \text {. }\end{array}$ \\
\hline $\begin{array}{l}\text { Koschei the immortal and anti-aging drugs. } \\
\text { Blagosklonny MV. Cell Death Dis. } 20145 \text { e1552. }\end{array}$ & & $\begin{array}{l}\text { Review of rapamycin protection against various } \\
\text { senescent pathologies (including in humans), and also } \\
\text { obesity. High rapamycin mimics starvation-induced } \\
\text { pseudo-diabetes (benign, reversible glucose } \\
\text { intolerance). Effects of rapamycin could be enhanced } \\
\text { by exercise, low calorie diet and combination with } \\
\text { other drugs (e.g. metformin, aspirin, angiotensin II } \\
\text { receptor blockers). }\end{array}$ \\
\hline $\begin{array}{l}\text { Geroconversion: irreversible step to cellular } \\
\text { senescence. Blagosklonny MV. Cell Cycle } 2014 \\
13 \text { 3628-3635. }\end{array}$ & & $\begin{array}{l}\text { Reiterates the two stage (quiescence, geroconversion) } \\
\text { model of cell senescence, emphasizing the importance } \\
\text { of the latter in disease etiology. }\end{array}$ \\
\hline $\begin{array}{l}\text { Rejuvenating immunity: "anti-aging drug } \\
\text { today" eight years later. Blagosklonny MV. } \\
\text { Oncotarget } 2015619405-19412 .\end{array}$ & & $\begin{array}{l}\text { Response to Sci Transl Med. } 20146268 \mathrm{ra} 179 \text { showing } \\
\text { that Everolimus improves immune function in the } \\
\text { elderly. Reiterates mTOR-centric model, and the } \\
\text { potential of mTOR inhibitors to retard aging. }\end{array}$ \\
\hline $\begin{array}{l}\text { From rapalogs to anti-aging formula. } \\
\text { Blagosklonny MV. Oncotarget } 20178 \text { 35492- } \\
\text { 35507. }\end{array}$ & & $\begin{array}{l}\text { Updates Koschei formula paper (2014), discussing } \\
\text { how anti-aging drugs could be combined. } \\
\text { Accumulating evidence of effects against multiple } \\
\text { senescent pathologies of e.g. angiotensin II inhibitors, } \\
\text { aspirin, PDE5 inhibitors. }\end{array}$ \\
\hline $\begin{array}{l}\text { Does rapamycin slow down time? } \\
\text { Blagosklonny MV. Oncotarget } 20189 \text { 30210- } \\
\text { 30212. }\end{array}$ & * & $\begin{array}{l}\text { Short review viewing rate of developmental processes } \\
\text { in senescence as biological time, and noting effects of } \\
\text { mTOR/rapamycin on biological clocks (circadian, } \\
\text { epigenetic). }\end{array}$ \\
\hline $\begin{array}{l}\text { Disease or not, aging is easily treatable. } \\
\text { Blagosklonny MV. Aging } 2018103067-3078 .\end{array}$ & * & $\begin{array}{l}\text { Account of aging as clinical diseases, their pre- } \\
\text { diseases, and pre-pre-diseases in the primary causes of } \\
\text { aging (hyperfunction). }\end{array}$ \\
\hline $\begin{array}{l}\text { Rapamycin, proliferation and geroconversion } \\
\text { to senescence. Blagosklonny MV. Cell Cycle } \\
2018172655-2665 \text {. }\end{array}$ & & $\begin{array}{l}\text { Updated reiteration of the two stage (quiescence, } \\
\text { geroconversion) model of cell senescence, including } \\
\text { discussion of the problem of defining cellular } \\
\text { senescence in vivo. }\end{array}$ \\
\hline $\begin{array}{l}\text { Paradoxes of senolytics. Blagosklonny MV. } \\
\text { Aging } 2018104289-4293 \text {. }\end{array}$ & $*$ & $\begin{array}{l}\text { Senolytic drugs counteract hyperfunction not damage. } \\
\text { Discussion of absolute vs relative hyperfunction. }\end{array}$ \\
\hline $\begin{array}{l}\text { The mystery of the ketogenic diet: benevolent } \\
\text { pseudo-diabetes. Blagosklonny MV. Cell Cycle } \\
201918 \text { 2157-2163. }\end{array}$ & & $\begin{array}{l}\text { Like rapamycin, ketogenic diets (KDs) extend mouse } \\
\text { lifespan and induce pseudo-diabetes. KDs (e.g. Atkins } \\
\text { diet) have promise as treatments for human aging. }\end{array}$ \\
\hline $\begin{array}{l}\text { Fasting and rapamycin: diabetes versus } \\
\text { benevolent glucose intolerance. Blagosklonny } \\
\text { MV. Cell Death Dis. } 201910607 .\end{array}$ & & $\begin{array}{l}\text { Updated reiteration of how high rapamycin mimics } \\
\text { starvation-induced pseudo-diabetes (benign, } \\
\text { reversible glucose intolerance). }\end{array}$ \\
\hline
\end{tabular}




\begin{tabular}{|l|l|l|}
\hline $\begin{array}{l}\text { Rapamycin for longevity: opinion article. } \\
\text { Blagosklonny MV. Aging } 2019118048-8067 .\end{array}$ & $*$ & $\begin{array}{l}\text { Updated recapitulation of potential of rapamycin as } \\
\text { an anti-aging drug, including critique of arguments } \\
\text { against this. }\end{array}$ \\
\hline $\begin{array}{l}\text { Rapamycin for the aging skin. Blagosklonny } \\
\text { MV. Aging } 201911 \text { 12822-12826. }\end{array}$ & $*$ & $\begin{array}{l}\text { Response to Geroscience } 201941861 \text { study showing } \\
\text { that topical rapamycin ameliorates skin senescence. }\end{array}$ \\
\hline $\begin{array}{l}\text { From causes of aging to death from COVID-19 } \\
\text { Blagosklonny MV. Aging } 202012 \text { 10004-10021. }\end{array}$ & & $\begin{array}{l}\text { Quasi-programmed hyperfunction, promoted by } \\
\text { mTOR, contributes to inflammaging, leading to lethal } \\
\text { cytokine storms and increased death rates in older } \\
\text { COVID-19 patients. }\end{array}$ \\
\hline $\begin{array}{l}\text { The goal of geroscience is life extension } \\
\text { Blagosklonny MV. Oncotarget 2021 12 131-144. }\end{array}$ & $\begin{array}{l}\text { Critique of the use of increased healthspan rather than } \\
\text { increased lifespan as criterion for identifying anti- } \\
\text { aging drugs using animal models. Reviews effects of } \\
\text { diverse drugs on lifespan in animal models. }\end{array}$ \\
\hline $\begin{array}{l}\text { DNA- and telomere-damage does not limit } \\
\text { lifespan: evidence from rapamycin } \\
\text { Blagosklonny. MV. Aging 2021 13 3167-3175. }\end{array}$ & $*$ & $\begin{array}{l}\text { Recent studies show that rapamycin does not increase } \\
\text { lifespan in DNA repair- and telomerase-deficient } \\
\text { mice. Argues that this is evidence that DNA damage } \\
\text { is not life limiting in normal aging. Good example of } \\
\text { use of the onion model (see glossary). }\end{array}$ \\
\hline $\begin{array}{l}\text { Response to the thought-provoking critique of } \\
\text { hyperfunction theory by Aubrey de Grey } \\
\text { Blagosklonny, MV. Rejuvenation Res. 2021 24 } \\
\text { 170-172. }\end{array}$ & $\begin{array}{l}\text { Rebuttal to various objections defending the damage } \\
\text { maintenance paradigm, similar in character to those } \\
\text { made by P. Zimniak. See Aging 2012 } 4861 .\end{array}$ \\
\hline
\end{tabular}

Stars indicate estimates of impact in terms of aging theory. ${ }^{* *}$, key source presenting major new ideas. ${ }^{* *}$, presents notable new concepts or perspectives. ${ }^{*}$, notable minor additions to the ideas framework. Where ideas are presented in several different essays, the first presentation is usually treated as more important. 